Prepared for the

U.S. Nuclear Regulatory Commission under a Related Services Agreement

with the U.S. Department of Energy

Contract DE-AC05-76RL01830

\title{
Improvements in 500-kHz Ultrasonic Phased-Array Probe Designs for Evaluation of Thick Section Cast Austenitic Stainless Steel Piping Welds
}

SL Crawford

AD Cinson

TL Moran
MT Anderson

AA Diaz

February 2011

Pacific Northwest

NATIONAL LABORATORY

Proudly Operated by Battelle Since 1965 


\title{
DISCLAIMER
}

This report was prepared as an account of work sponsored by an agency of the United States Government. Neither the United States Government nor any agency thereof, nor Battelle Memorial Institute, nor any of their employees, makes any warranty, express or implied, or assumes any legal liability or responsibility for the accuracy, completeness, or usefulness of any information, apparatus, product, or process disclosed, or represents that its use would not infringe privately owned rights. Reference herein to any specific commercial product, process, or service by trade name, trademark, manufacturer, or otherwise does not necessarily constitute or imply its endorsement, recommendation, or favoring by the United States Government or any agency thereof, or Battelle Memorial Institute. The views and opinions of authors expressed herein do not necessarily state or reflect those of the United States Government or any agency thereof.

\author{
PACIFIC NORTHWEST NATIONAL LABORATORY \\ operated by \\ BATTELLE \\ for the \\ UNITED STATES DEPARTMENT OF ENERGY \\ under Contract DE-AC05-76RL01830 \\ Printed in the United States of America
Available to DOE and DOE contractors from the
Office of Scientific and Technical Information,
P.O. Box 62, Oak Ridge, TN 37831-0062;
ph: (865) 576-8401
fax: (865) 576-5728
email: reports@adonis.osti.gov

\author{
Available to the public from the National Technical Information Service, \\ U.S. Department of Commerce, 5285 Port Royal Rd., Springfield, VA 22161 \\ ph: (800) 553-6847 \\ fax: (703) 605-6900 \\ email: orders@ntis.fedworld.gov \\ online ordering: http://www.ntis.gov/ordering.htm
}

This document was printed on recycled paper. 


\title{
Improvements in 500-kHz Ultrasonic Phased-Array Probe Designs for Evaluation of Thick Section Cast Austenitic Stainless Steel Piping Welds
}

\author{
SL Crawford \\ MT Anderson \\ AD Cinson \\ AA Diaz \\ TL Moran
}

February 2011

Prepared for

U.S. Nuclear Regulatory Commission under a Related Services Agreement with the U.S. Department of Energy

Contract DE-AC05-76RL01830

Pacific Northwest National Laboratory

Richland, Washington 99352 



\section{Summary}

PNNL has been studying and performing confirmatory research on the inspection of piping welds in coarse-grained steels for over 30 years. More recent efforts have been the application of low frequency phased array technology to this difficult to inspect material. The evolution of $500 \mathrm{kHz}$ PA probes and the associated electronics and scanning protocol are documented in this report. The basis for the probe comparisons are responses from one mechanical fatigue crack and two thermal fatigue cracks in largebore cast mockup specimens on loan from the Electric Power Research Institute.

One of the most significant improvements was seen in the use of piezo-composite elements in the later two probes instead of the piezo-ceramic material used in the prototype array. This allowed a reduction in system gain of $30 \mathrm{~dB}$ and greatly reduced electronic noise. The latest probe had as much as a $5 \mathrm{~dB}$ increase in signal to noise, adding to its flaw discrimination capability. The system electronics for the latest probe were fully optimized for a $500 \mathrm{kHz}$ center frequency, however significant improvements were not observed in the center frequency of the flaw responses. With improved scanner capabilities, smaller step sizes were used, allowing both line and raster data improvements to be made with the latest probe. The small step sizes produce high resolution images that improve flaw discrimination and, along with the increased signal-to-noise ratio inherent in the latest probe design, enhanced detection of the upper regions of the flaw make depth sizing more plausible. Finally, the physical sizes of the probes were progressively decreased allowing better access to the area of interest on specimens with weld crowns, and the latest probe was designed with non-integral wedges providing flexibility in focusing on different specimen geometries. 



\section{Acronyms and Abbreviations}

ASME

BW

CASS

CCSS

CEA

$\mathrm{dB}$

EPRI

FFT

ID

IRSN

MFC

NDE

NRC

OD

PA

PNNL

PWROG

rf

SAFT

SCSS

SNR

TFC

TLR

TRL

WSS
American Society of Mechanical Engineers

bandwidth

cast austenitic stainless steel

centrifugally cast stainless steel

Commissariat à L'Énergie Atomique

decibels

Electric Power Research Institute

Fast Fourier Transform

inner diameter

Institute for Radioprotection and Nuclear Safety

mechanical fatigue crack

nondestructive examination

U.S. Nuclear Regulatory Commission

outer diameter

phased array

Pacific Northwest National Laboratory

pressurized water reactor owner's group

radio frequency

Synthetic Aperture Focusing Technique

statically cast stainless steel

signal-to-noise ratio

thermal fatigue crack

technical letter report

transmit-receive longitudinal

wrought stainless steel 



\section{Contents}

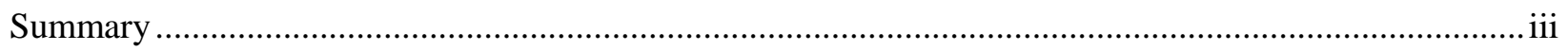

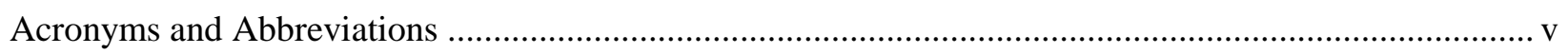

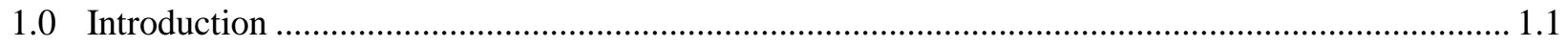

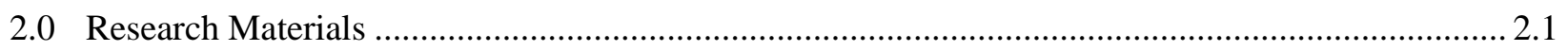

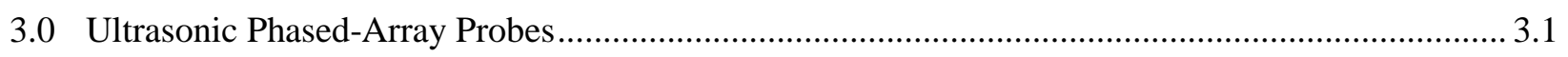

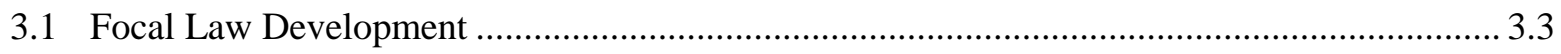

4.0 Ultrasonic Phased-Array Acquisition Configuration.............................................................. 4.1

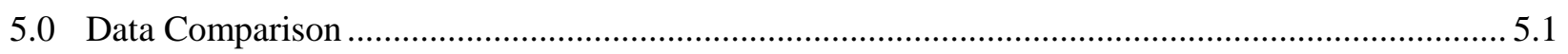

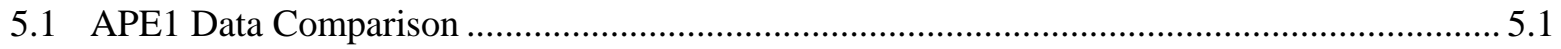

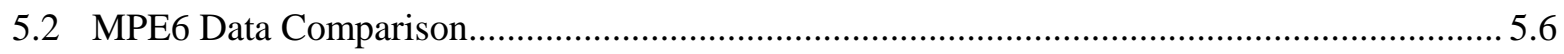

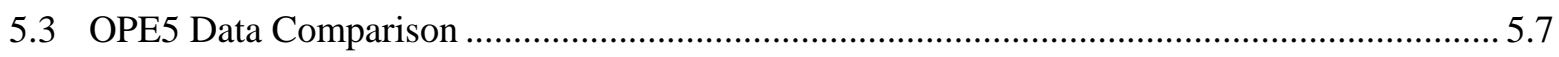

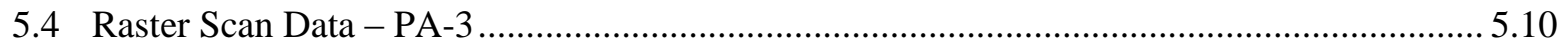

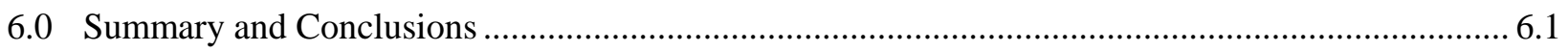

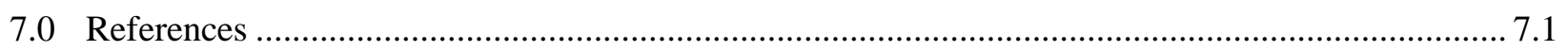




\section{Figures}

2.1 Polished and Etched Cross Section of Specimen APE1 ........................................................ 2.2

2.2 Polished and Etched Cross Section of Specimen MEP6............................................................. 2.2

2.3 Polished and Etched Cross Section of Specimen OPE2 …....................................................... 2.3

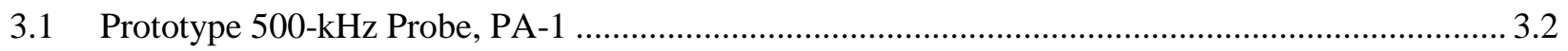

3.2 Second Design, PA-2, on the Right and Third Design, PA-3, with a Removable Wedge on

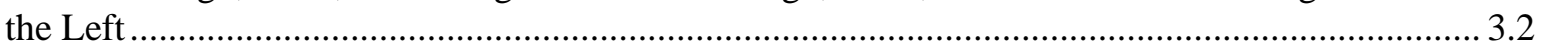

3.3 PA-1 Top Left is Steered to 1.1 Degrees, PA-2 Top Right is Steered to 1.1 Degrees, and PA-3 Bottom is Steered to -3.9 Degrees in Their Respective Wedges to Generate a Refracted 45-degree Angle in Steel ........................................................................................ 3.5

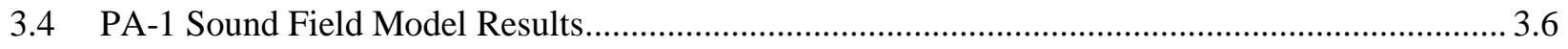

3.5 PA-2 Sound Field Model Results............................................................................................. 3.6

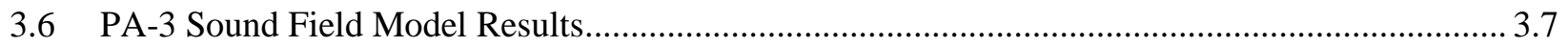

5.1 PA-1 Data from APE1 at 3.5 Inches from the Weld Centerline …........................................... 5.2

5.2 PA-2 Data from APE1 at 3.0 Inches from the Weld Centerline .................................................... 5.2

5.3 PA-3 Data from APE1 at 2.5 Inches from the Weld Centerline ..................................................... 5.3

5.4 PA-1 Data with a Center Frequency of $0.42 \mathrm{MHz}$ and an 82\% Bandwidth.................................. 5.4

5.5 PA-2 Data with a Center Frequency of $0.49 \mathrm{MHz}$ and a $60 \%$ BW........................................... 5.4

5.6 PA-3 Data with a Center Frequency of $0.46 \mathrm{MHz}$ and a 73.7\% BW .......................................... 5.5

5.7 PA-1 Data from MPE6 at 3.5 Inch from the Weld Centerline ................................................... 5.6

5.8 PA-2 Data from MPE6 at 3.0 Inch from the Weld Centerline ......................................................... 5.7

5.9 PA-3 Data from MPE6 at 3.0 Inch from the Weld Centerline ..................................................... 5.7

5.10 PA-1 Data from OPE5 at 3.0 Inch from the Weld Centerline..................................................... 5.8

5.11 PA-2 Data from OPE5 at 2.0 Inch from the Weld Centerline..................................................... 5.9

5.12 PA-3 Data from OPE5 at 2.0 Inch from the Weld Centerline...................................................... 5.9

5.13 PA-3 Data from OPE5 at 2.5 Inch from the Weld Centerline................................................... 5.10

5.14 Raster Data from INEA4 Showing a Strong ID Signal from the Flaw with a Possible Signal from the Upper Part of the Crack Marked by Arrows................................................................ 5.10

\section{Tables}

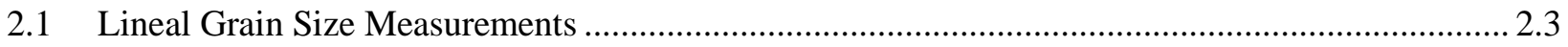

3.1 Specifications of the Phased Array Probes ........................................................................... 3.2

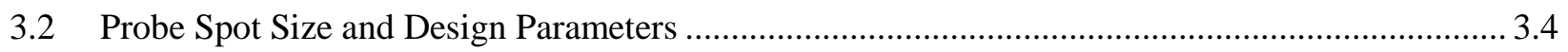

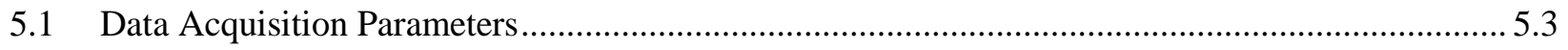

5.2 Signal-to-Noise Values From APE1 Flaw, CCSS Side ............................................................ 5.5 


\subsection{Introduction}

This document is a technical letter report summarizing the progression in design and application of low frequency, $500 \mathrm{kHz}$, ultrasonic phased array (PA) probes employed at the Pacific Northwest National Laboratory (PNNL) in Richland, Washington, for evaluating thick-walled cast austenitic stainless steel (CASS) piping welds. The evolution in PA probe design was preceded by over 30 years of research in the application of conventional low frequency probes in conjunction with Synthetic Aperture Focusing Technique (SAFT), (Anderson et al. 2007, Diaz et al. 1998, Taylor 1984) for inspecting coarse grained reactor components. In addition to the changes in probe design, system electronics and scanner apparatus have been improved and are discussed. The work reported here was conducted as part of a U.S. Nuclear Regulatory Commission (NRC) project at PNNL entitled, "Reliability of Nondestructive Examination for Nuclear Power Plant In-service Inspection," under Task 2 of JCN-N6398. A primary objective of this work is to evaluate various nondestructive evaluation (NDE) methods to assess their ability to detect, localize, and size cracks in these components. This technical letter report (TLR) is deliverable number NRC - D21 under a cooperative program between the NRC, PNNL, the French Institute for Radioprotection and Nuclear Safety (IRSN) and the French Commissariat à L'Énergie Atomique (CEA), on the evaluation and modeling of coarse grained components. This international cooperative program is covered under Task 1B of JCN-N6398.

This report will present data obtained from several components from the Pressurized Water Reactor Owner's Group (PWROG) set of welded specimens. These data sets form the basis for comparing evolving capabilities in operation of three PA probes. Section 2 of this report describes the PWROG specimens. Section 3 provides a description of the PA probes, and Section 4 presents details on the instrumentation and scanning devices. Section 5 provides a data comparison for the PA probes, Section 6 presents the conclusions from this work, and Section 7 is a list of references. 



\subsection{Research Materials}

The flawed piping specimens used in this study are part of a set of PWROG components on loan from the Electric Power Research Institute (EPRI). These mock-ups contain centrifugally cast stainless steel (CCSS) pipes-to-statically cast stainless steel (SCSS) elbows, SCSS elbows-to-wrought stainless steel (WSS) safe ends, and CCSS pipes-to-SCSS pump nozzle configuration. The specimens contain inside surface-breaking thermal or mechanical fatigue cracks (TFC or MFC, respectively), with depths reported in the range of 13 to 42 percent through-wall and are located on either side of the weld centerline. The MFCs are typically linear in nature while the TFCs exhibit branching. All flaws are circumferentially oriented. Specimen dimensions vary but are nominally $260 \mathrm{~mm}$ (10.2 in.) circumferential segments, $610 \mathrm{~mm}$ (24.0 in.) in axial extent, and approximately 58 to $90 \mathrm{~mm}$ (2.2 to $3.5 \mathrm{in}$.) in thickness. The three specimens considered in this report are APE1, MPE6 and OPE5, as viewed from the CCSS side of the weld. Each specimen is a statically cast elbow section to a centrifugally cast pipe section. In specimen APE1 the elbow side is $88.9 \mathrm{~mm}$ (3.5 in.) thick and the pipe side is $66 \mathrm{~mm}$ (2.6 in.) thick with a MFC on the elbow side of the weld centerline. Specimen MPE6 has an $83.8 \mathrm{~mm}$ (3.3 in.) thick elbow side and a $66 \mathrm{~mm}$ (2.6 in.) pipe side with a TFC on the elbow side. Finally specimen OPE5 has a $71.1 \mathrm{~mm}(2.8 \mathrm{in}$.) thick elbow side and a $58.4 \mathrm{~mm}$ (2.3 in.) thick pipe side with a TFC on the elbow side.

The specimens were polished and chemically etched to reveal the grain microstructure. Figures 2.1 through 2.3 display the microstructure in a false color-coded format where regions with similar grains are given the same color. As the images show, these materials are banded with columnar and equiaxed regions in the same specimen. The mean lineal intercepts are listed in the figures and give an indication of the grain sizes in each color-coded region as measured along a horizontal line. The CCSS side of specimen APE1 contains regions with mean lineal intercepts of 1.52 and $1.77 \mathrm{~mm}$ (0.06 and $0.07 \mathrm{in}$.). Specimen OPE5, CCSS side, has regions with 1.13, 2.42 and $1.68 \mathrm{~mm}(0.04,0.10$ and $0.07 \mathrm{in}$.) lineal intercepts. The third specimen considered, MPE6, has the largest grains on the CCSS side at 2.27, 2.20 and $3.00 \mathrm{~mm}(0.09,0.09$, and $0.12 \mathrm{in}$.) measured mean lineal intercept. A summary of the cast material minimum and maximum grain diameters as measured from the polished and etched planes are listed in Table 2.1 (Anderson et al. 2007). From these listed values, one can observe a large range of maximum grain sizes in this material. The APE1 material has a maximum grain diameter of $8.86 \mathrm{~mm}$ (0.35 in.), which is approximately three times smaller than the MPE6 material with a maximum dimension of $26.81 \mathrm{~mm}$ (1.06 in.). These large grains increase the scattering and beam redirection taking place and thus reduce the effectiveness of the ultrasonic inspection as shown in the data. 


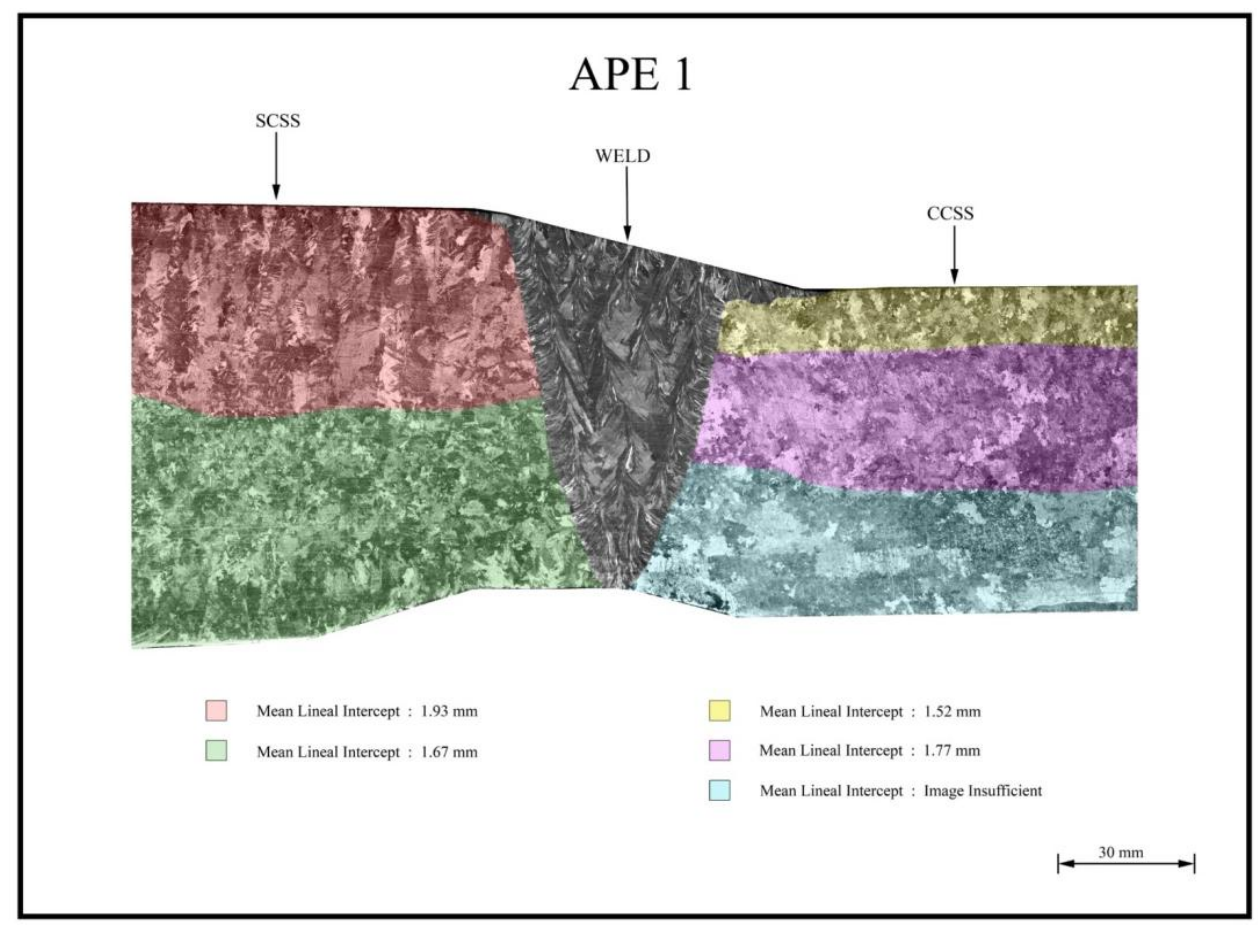

Figure 2.1. Polished and Etched Cross Section of Specimen APE1

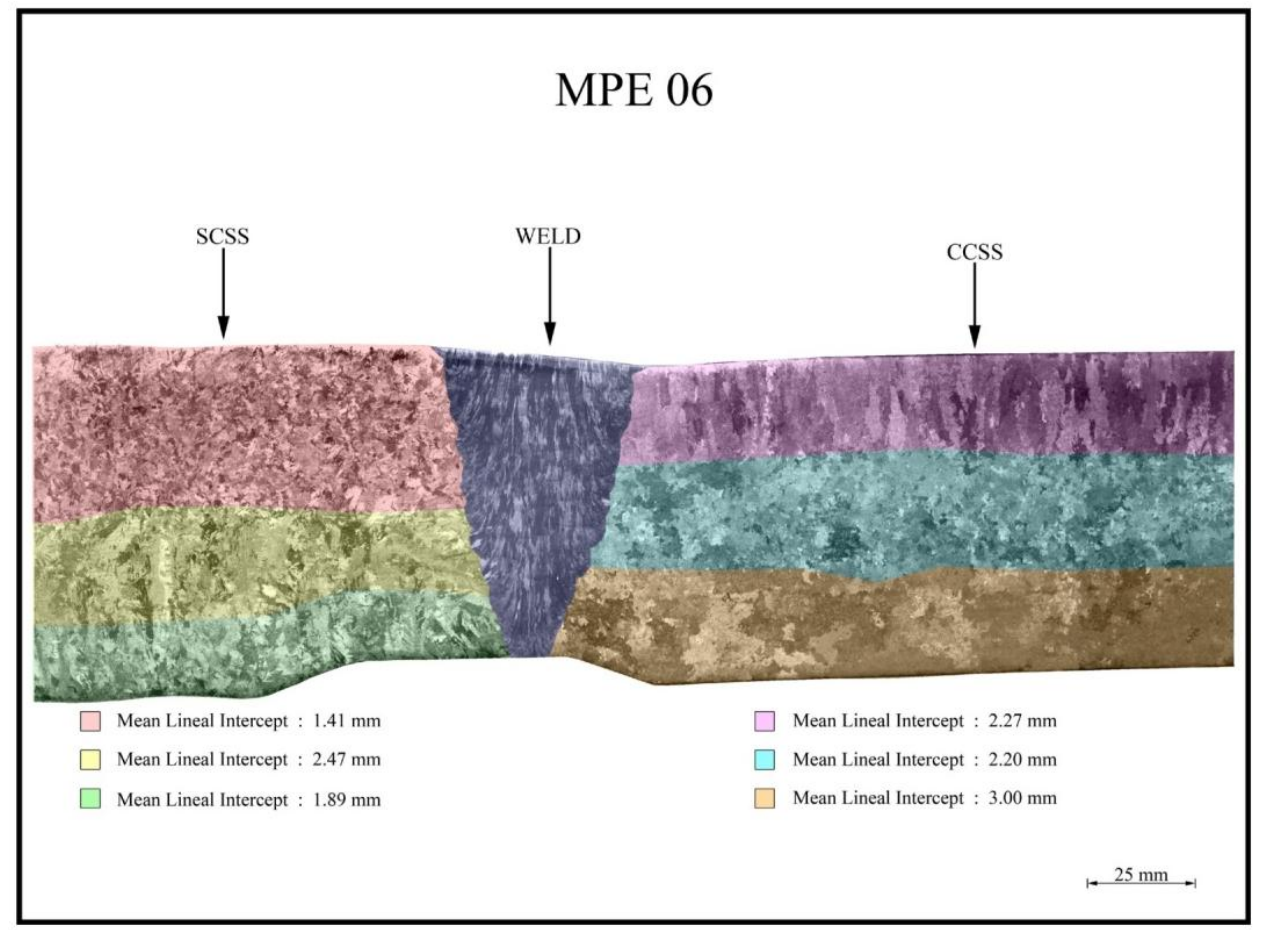

Figure 2.2. Polished and Etched Cross Section of Specimen MEP6 


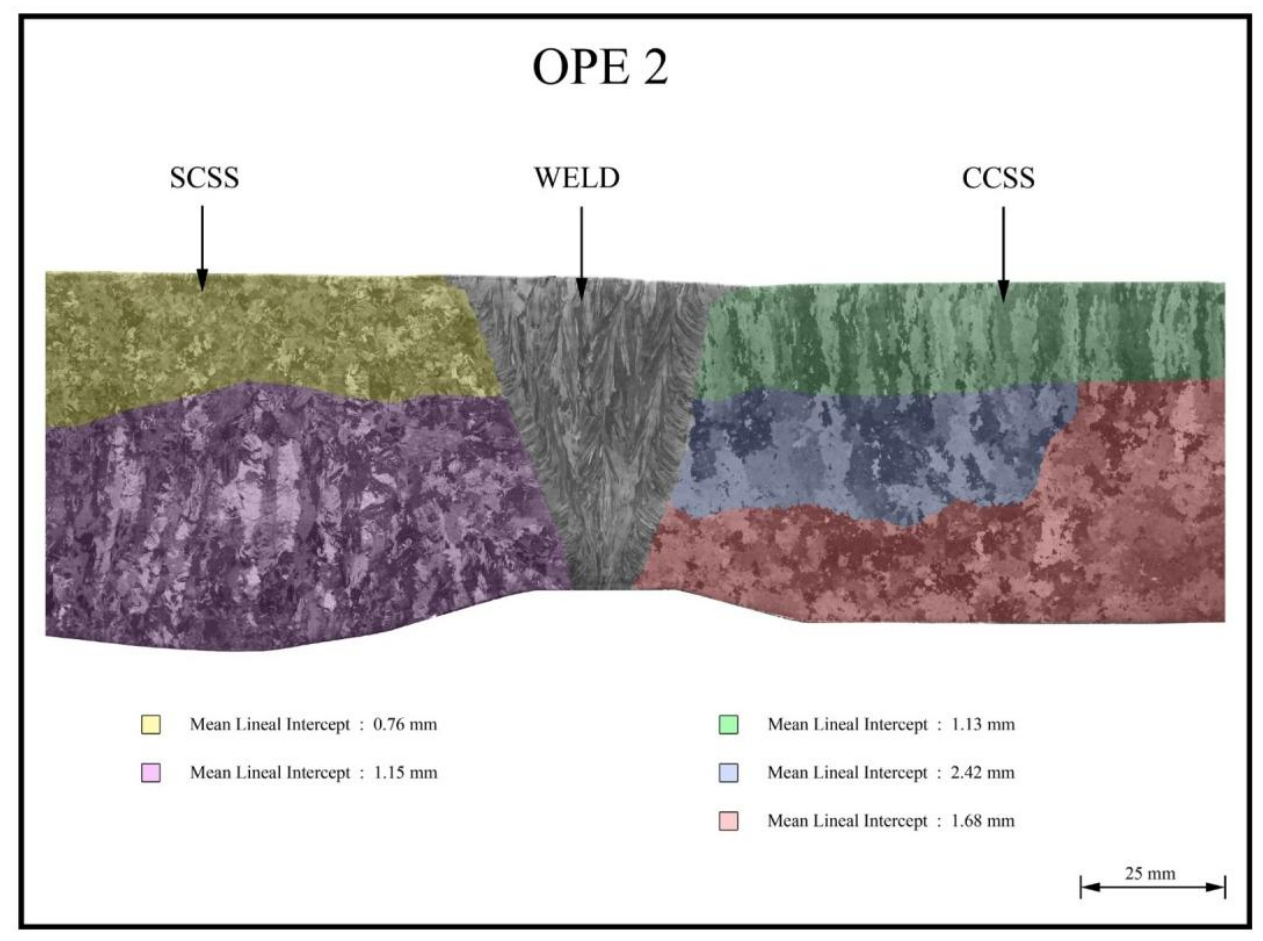

Figure 2.3. Polished and Etched Cross Section of Specimen OPE2

Table 2.1. Lineal Grain Size Measurements

\begin{tabular}{lcccc}
\hline & \multicolumn{2}{c}{ CCSS } & \multicolumn{2}{c}{ SCSS } \\
\cline { 2 - 5 } \multicolumn{1}{c}{ Specimen } & $\begin{array}{c}\text { Minimum, } \\
\text { mm (in.) }\end{array}$ & $\begin{array}{c}\text { Maximum, } \\
\text { mm (in.) }\end{array}$ & $\begin{array}{c}\text { Minimum, } \\
\text { mm (in.) }\end{array}$ & $\begin{array}{c}\text { Maximum, } \\
\text { mm (in.) }\end{array}$ \\
\hline APE-1 & $0.44(0.02)$ & $8.86(0.35)$ & $0.89(0.03)$ & $9.31(0.37)$ \\
MPE-6 & $0.56(0.02)$ & $26.81(1.06)$ & $0.28(0.01)$ & $5.59(0.22)$ \\
OPE-5 & $0.21(0.01)$ & $16.67(0.66)$ & $0.21(0.01)$ & $5.21(0.21)$ \\
\hline
\end{tabular}





\subsection{Ultrasonic Phased-Array Probes}

The CASS PWROG specimens were examined using three, progressively improving, low-frequency transmit-receive-longitudinal (TRL) phased-array probes. All probes were designed to have a center frequency of 500-kHz, yielding a theoretical wavelength of $11.5 \mathrm{~mm}(0.45 \mathrm{in}$.) in wrought stainless steel materials, which are essentially isotropic. The longer wavelength improves the overall penetration of the ultrasonic energy into the coarse-grained CASS material allowing for better insonification of the targeted region of interest. As the wavelength is increased (relative to the size of the average grain diameters), the scatter in the sound field is reduced, making the sound field less sensitive to the effects of the largegrained microstructure. Attenuation is also reduced at lower frequencies. The only negative effect that is encountered at these low frequencies is a loss of spatial resolution due to the large wavelengths involved. Each of the probes used in this study have wedges that were curved to match the approximate outer diameter (OD) of the specimens examined. The nominal specimen OD is $914 \mathrm{~mm}$ (36 in.).

The first probe, PA-1, was a prototype array developed by Michel DeLaide at AIB-Vincotte in Belgium. A photograph of this probe is shown as Figure 3.1; technical specifications are listed in Table 3.1. The probe is designed with an integral wedge having an angle of 15.4 degrees that refracts the UT beam (if no phasing of elements is performed) at 41 degrees in steel. It also possesses a roof angle between the transmit and receive segments of 6.1 degrees, which provides a natural cross-over focal point of $76 \mathrm{~mm}$ (3.0 in.) in steel. The prototype transducer was fabricated in late 2003 with piezo-ceramic elements, which, at that time, were the only materials available at $500 \mathrm{kHz}$. This array was loaned to PNNL and used to perform feasibility evaluations on the large bore CASS PWROG specimens.

The second probe, PA-2, was fabricated with piezo-composite material. This material typically produces a broader bandwidth and requires less gain to drive the elements, resulting in improved dynamic range. The probe has an integral wedge design with a total of 32 elements in each of the transmitting and receiving sides of the array $[2 \times(8 \times 4)$-element TRL configuration]. Similar to the prototype, it has a wedge angle of 15.4 degrees and a roof angle of 6.1 degrees. The four elements in the lateral direction give this probe the ability to skew, or steer, the sound field from side-to-side, which was another design enhancement over the prototype array. The probe is shown on the right side of Figure 3.2 and its specifications are also listed in Table 3.1. The probe footprint in the active array (forward) direction is $30 \mathrm{~mm}$ (1.2 in.) smaller than the PA-1 footprint, allowing closer access to a flaw for multiple phased angles, especially in cases where OD weld surfaces are not ground flush. This shortened footprint is significant and can easily make the difference in flaw detection for welds with large crowns. 


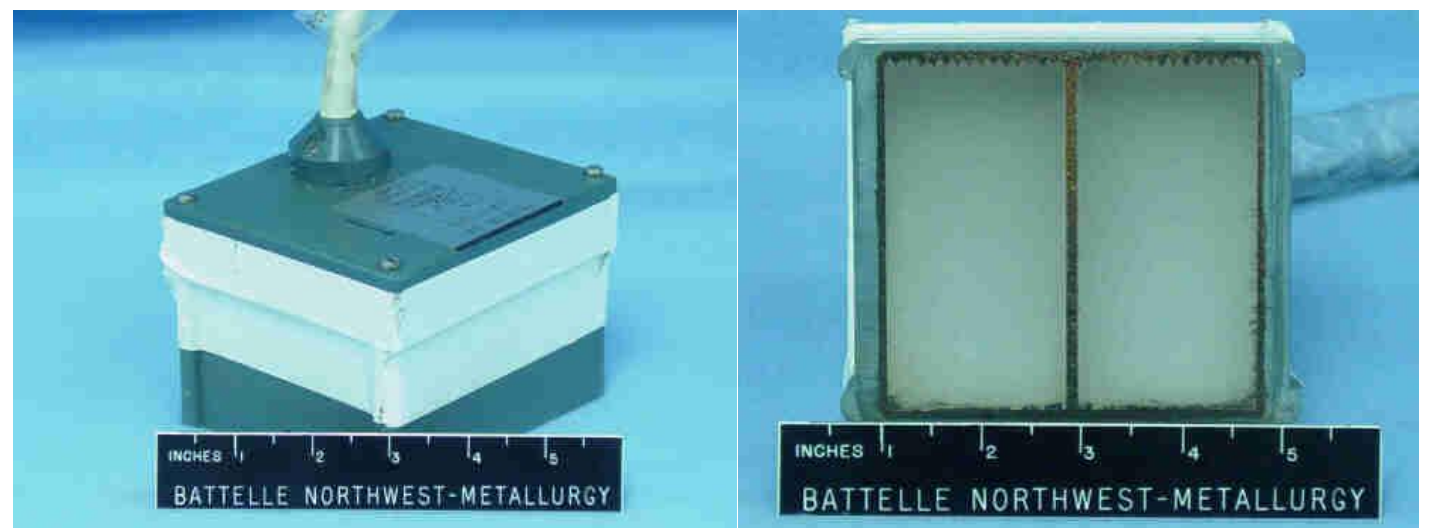

Figure 3.1. Prototype 500-kHz Probe, PA-1

Table 3.1. Specifications of the Phased Array Probes

\begin{tabular}{llll}
\cline { 2 - 4 } & \multicolumn{1}{c}{ PA-1 } & \multicolumn{1}{c}{ PA-2 } & \multicolumn{1}{c}{ PA-3 } \\
\hline Material & Piezo-ceramic & Piezo-composite & Piezo-composite \\
Configuration & $2 \times(10 \times 2)$ & $2 \times(8 \times 4)$ & $2 \times(10 \times 5)$ \\
Element length & $7.44 \mathrm{~mm}(0.29 \mathrm{in})$. & $9.19 \mathrm{~mm}(0.36 \mathrm{in})$. & $6.5 \mathrm{~mm}(0.26 \mathrm{in})$. \\
Element width & $20.2 \mathrm{~mm}(0.80 \mathrm{in})$. & $9.29 \mathrm{~mm}(0.37 \mathrm{in})$. & $7.0 \mathrm{~mm}(0.28 \mathrm{in})$. \\
Active aperture & $84 \mathrm{~mm}(3.31 \mathrm{in})$. & $72.8 \mathrm{~mm}(2.87 \mathrm{in})$. & $65 \mathrm{~mm}(2.6 \mathrm{in})$. \\
Passive aperture & $42 \mathrm{~mm}(1.65 \mathrm{in})$. & $36.4 \mathrm{~mm}(1.43 \mathrm{in})$. & $35 \mathrm{~mm}(1.4 \mathrm{in})$. \\
Total footprint (includes housing) & $115 \times 115 \mathrm{~mm}$ & $85 \times 85 \mathrm{~mm}$ & $80 \times 83 \mathrm{~mm}$ \\
& $(4.5 \times 4.5 \mathrm{in})$. & $(3.35 \times 3.35 \mathrm{in})$. & $(3.15 \times 3.27 \mathrm{in})$. \\
Wedge angle (deg) & 15.4 & 15.4 & 20.5 \\
Refracted angle $(\mathrm{deg})$ & 41 & 41 & 60 \\
Identification & TS40059A1-R450AX & TS40059M4B & $05 \mathrm{M} 10 \times 5 \mathrm{E} 65-35$ \\
& & & $7116 \mathrm{~A} 101$ \\
\hline
\end{tabular}

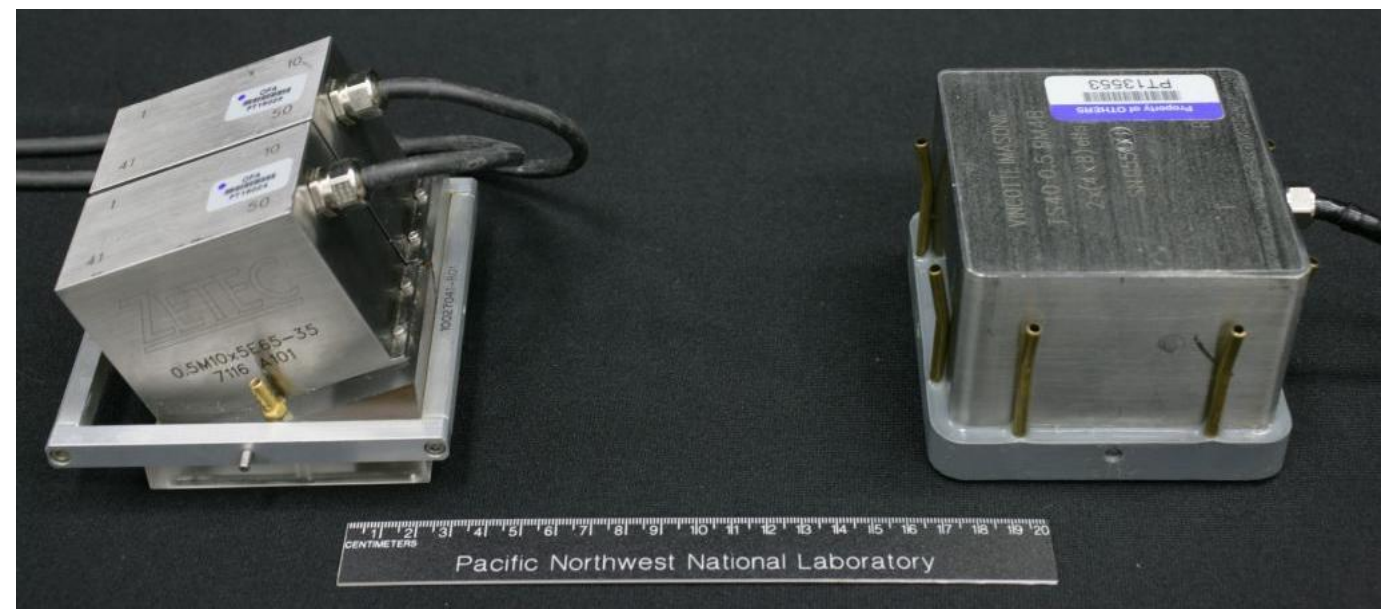

Figure 3.2. Second Design, PA-2, on the Right and Third Design, PA-3, with a Removable Wedge on the Left. The scale in the foreground is in centimeter units, approximately 0 to $20.5 \mathrm{~cm}$ (8.1 in.). 
The latest array, PA-3, at $2 \times(10 \times 5)$ elements, improves upon PA-2 in several ways, including a nonintegral design that allows wedges to be tailored for specific applications. This inherently provides increased variability in steering and focusing of the UT beam, for application to many specimen geometries. The probe's five lateral elements produce increased lateral beam skewing as well. PA-3 is displayed on the left portion of Figure 3.2 and its characteristics are listed in Table 3.1. The probe has $>50 \%$ bandwidth as measured at the $-6 \mathrm{~dB}$ points and possesses the smallest footprint of the three arrays. The actual wedge has a total width of $102 \mathrm{~mm}$ (4.01 in.) to accommodate the water ports used for ultrasonic coupling. Its length in the forward direction is $5 \mathrm{~mm}(0.2 \mathrm{in}$.) shorter than the PA-2 probe. The transducers are mounted on a rexolite wedge with a 20.5 degree angle and no roof angle. The natural refracted angle in steel is 60 degrees and there is no natural cross over depth.

\subsection{Focal Law Development}

A "true depth" focusing option was used in developing focal laws for each of the probes. This approach theoretically focuses the sound field at a constant depth in the material, for all steered angles. Line scan data were acquired to form the basis for the data comparison. The specifics of the focal laws used for each probe are described below.

True-depth focusing with a focal depth of $75 \mathrm{~mm}$ (2.95 in.) in wrought stainless steel material was used for the prototype probe. In theory, focusing the sound field along a line of constant depth in each specimen enhances the capability to detect ID corner responses from flaws. The refracted angles were steered from 30 to 60 degrees in 1-degree increments. A phased-array calculator within the UltraVision software allows one to model the sound field of a particular probe. It assumes a homogeneous, isotropic material. From this model, the theoretical spot size at the specified focal depth along a 45-degree refracted angle was measured at $21.2 \mathrm{~mm}$ (0.85 in.) in the X-axis (forward direction) and $30.4 \mathrm{~mm}$ (1.2 in.) in the $\mathrm{Y}$-axis (lateral direction). These values were determined at the half amplitude, or $-6 \mathrm{~dB}$ points.

The true depth option was also used for the remaining two probes, with the focal depth set at $65 \mathrm{~mm}$ (2.56 in.) for PA-2, and $50 \mathrm{~mm}$ (1.97 in.) for PA-3. Beam steering was similar to the prototype array, with refracted angles ranging from 30 to 60 degrees azimuthally, at 1-degree resolution. The specimen thicknesses at the flaw locations varied from approximately $60-80 \mathrm{~mm}(2.4-3.2 \mathrm{in}$.), reinforcing the need for choosing focal depths to be in this range. The spot size for a 45-degree refracted angle at the $50 \mathrm{~mm}$ (1.97 in.) focal depth is $15.7 \mathrm{~mm}(0.62 \mathrm{in}$.) in the X-axis and $19.4 \mathrm{~mm}(0.76 \mathrm{in}$.) in the Y-axis at the $-6 \mathrm{~dB}$ points in the isotropic material simulation for the PA-2 probe. The PA-3 array beam simulation shows a more symmetrical spot size of $19.2 \mathrm{~mm}(0.76 \mathrm{in}$.) by $20.7 \mathrm{~mm}(0.81 \mathrm{in}$.$) , as measured at the$ $-6 \mathrm{~dB}$ level. A second set of focal laws were generated for use with the PA-3 probe when acquiring raster scan data. In this arrangement, a half path focusing option was explored. Focal laws were created that focused the beam at a constant distance from the probe for all angles rather than at a specified depth in the part. The theoretical spot size for this set of conditions at a depth of $50 \mathrm{~mm}(1.97 \mathrm{in}$.$) and$ 45 degrees is $19.0 \mathrm{~mm}(0.75 \mathrm{in}$.) by $21.89 \mathrm{~mm}(0.86 \mathrm{in}$.$) .$

Theoretical spot size data are summarized in Table 3.2. If it is assumed that the smallest flaw that can ideally be detected is half the probe spot size, then the smallest detectable flaws will be approximately $15.2,9.7$, and $10.4 \mathrm{~mm}(0.60,0.38$, and $0.41 \mathrm{in}$.) in circumferential length for the respective probes. The large grains further complicate the inspection. Referring to the previous grain size data, the maximum 
grains in specimen OPE5 at $16.7 \mathrm{~mm}$ are on the order of the probe spot size while the maximum grains $(28.8 \mathrm{~mm})$ in specimen MPE6 are generally larger than the probe spot size. Theoretically, the largest grains present an interface for full beam refraction and reflection.

Table 3.2. Probe Spot Size and Design Parameters

\begin{tabular}{lcccccc} 
& \multicolumn{3}{c}{ Beam Size $(\mathbf{m m})$} & \multicolumn{4}{c}{ Probe Parameters } \\
\hline Probe & Primary & Secondary & $\mathrm{d}(\mathrm{mm})$ & $\mathrm{L}(\mathrm{mm})$ & $\mathrm{N}$ & $\mathrm{Nd}(\mathrm{mm})$ \\
PA-1 & 21.2 & 30.4 & 8.44 & 20.2 & 10 & 84.4 \\
PA-2 & 15.7 & 19.4 & 9.19 & 9.3 & 8 & 73.5 \\
PA-3 & 19.2 & 20.7 & 6.5 & 7.0 & 10 & 65 \\
PA-3 raster & 19.0 & 21.89 & & & & \\
\hline
\end{tabular}

Calculations and simulations were conducted for each probe and wedge configuration to explore the theoretical beam focusing and generation of unwanted side or grating lobes in the sound field. In the simplified case with a linear array, the directivity function in the azimuthal plane $(\theta)$ and the side or nonazimuthal plane $(\phi)$ are given by Eq. (3.1) (Wooh and Shi 1999).

$$
\mathrm{H}(\theta, \phi)=\left|\operatorname{sinc}\left(\frac{\pi \mathrm{a} \sin \theta \cos \phi}{\lambda}\right) \times \sin \mathrm{c}\left(\frac{\pi \mathrm{L} \sin \theta \sin \phi}{\lambda}\right) \times \frac{\sin \mathrm{c}\left[(\pi \mathrm{d} / \pi)\left(\sin \theta_{\mathrm{s}}-\sin \theta \cos \phi\right) \mathrm{N}\right]}{\operatorname{sinc}\left[(\pi \mathrm{d} / \pi)\left(\sin \theta_{\mathrm{s}}-\sin \theta \cos \phi\right)\right]}\right|
$$

The equation is sensitive to the number of elements in the primary axis $(\mathrm{N})$ as well as the individual element pitch (d), and element size (a). Element pitch is defined as the center-to-center spacing, thus accounts for the gap between elements. Also included in the equation is the width of the elements in the secondary, or passive, direction (L). Some of these probe parameters are listed in Table 3.2. Simplified for the two-dimensional case in the azimuthal plane where $\phi$ is set to zero in Eq. (3.1) (Wooh and Shi 1999), the beam directivity equation for phase-steered ultrasound yields a normalized pressure versus angle, $H(\theta)$. Graphical representations of the beam at a specific steering angle, $\theta_{\mathrm{s}}$, can be plotted. After taking into consideration the fixed wedge angle for each probe configuration, only minimal grating lobe generation in the rexolite wedge material was observed in the probes. Figure 3.3 displays the results for the three probes steered accordingly to generate a 45-degree angle in steel. Since the PA-1 and PA-2 probes both have a natural refracted angle at 41-degrees in steel, they are steered an additional 1.1 degree in the wedge to generate the desired refracted angle of 45 degrees. The PA-3 probe naturally refracts at 60 degrees in steel so it is steered -3.9 degrees in the wedge to generate a 45 -degree refracted angle. With this greater steering angle, a grating lobe is evident at 40-degrees that exceeds $25 \%$ in amplitude. However this angle is beyond the first and second critical angles so would not introduce extraneous signals in the specimen. 


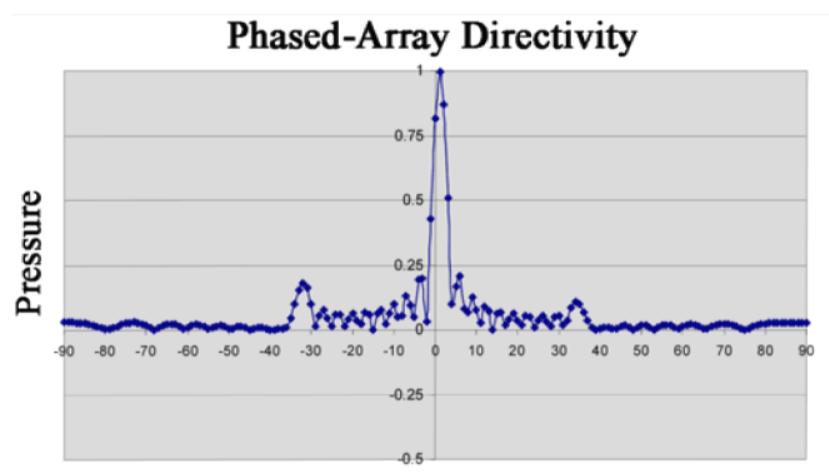

Measured Angle

Phased-Array Directivity

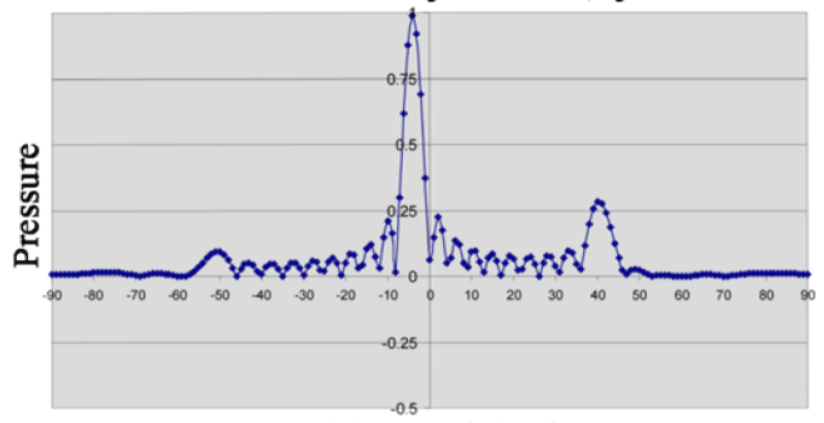

Measured Angle

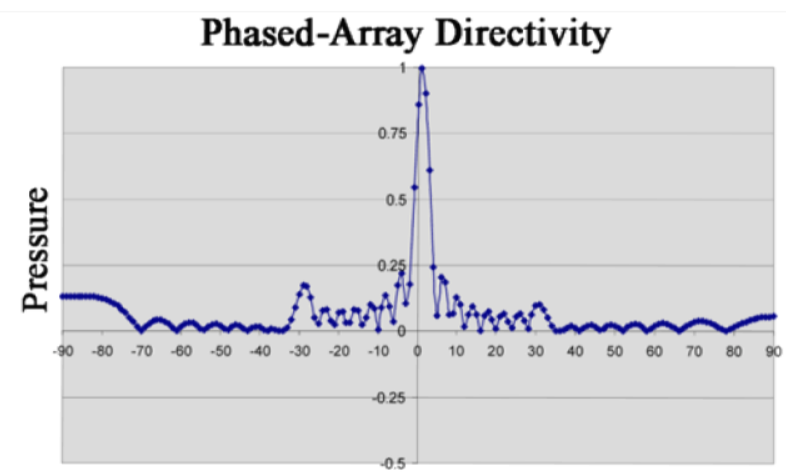

Measured Angle

Figure 3.3. PA-1 Top Left is Steered to 1.1 Degrees, PA-2 Top Right is Steered to 1.1 Degrees, and PA-3 Bottom is Steered to -3.9 Degrees in Their Respective Wedges to Generate a Refracted 45-degree Angle in Steel. The respective wedges were designed to naturally generate a 41, 41, and 60-degree refracted angle in steel.

Ultrasonic sound fields were also modeled in the ZETEC UltraVision ${ }^{\circledR}$ software and these data showed minimal grating or side lobe generation from each of the probes. Figures 3.4-3.6 display the azimuthal or side views at 30-, 45- and 60-degrees and the top views of the sound fields at 45-degrees as formed in the focal plane. The top views were used to determine the probe spot sizes. The azimuthal views also show the preference for sound generation at lower angles for all three probes. Because of this effect, there is often a strong reflection in the data from the specimen back surface at low angles. 


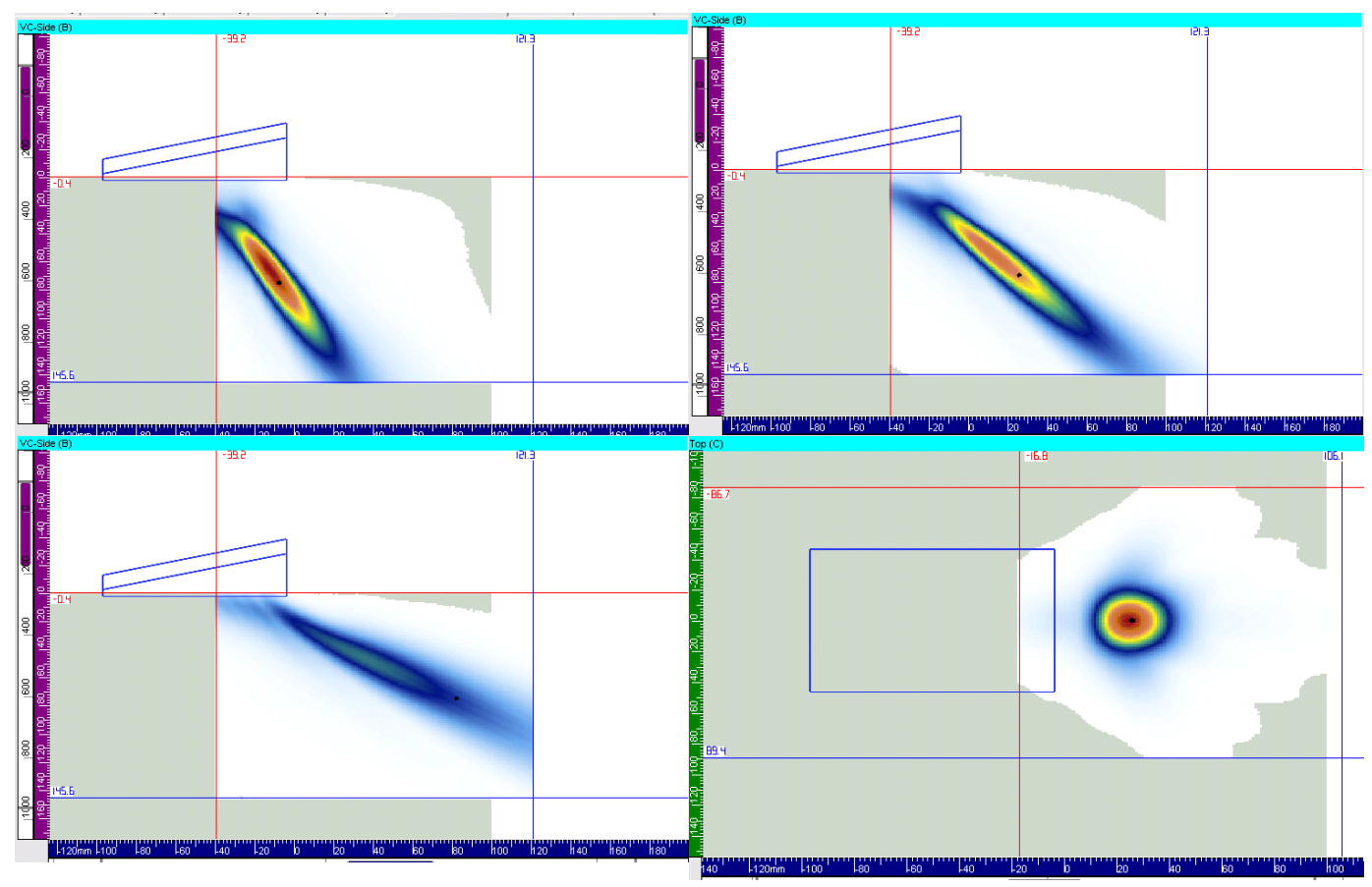

Figure 3.4. PA-1 Sound Field Model Results. The upper left image represents the 30 degree beam, the upper right the 45 degree beam and the lower left the 60 degree beam. The lower right image represents the top view of the 45 degree beam in the focal plane of $75 \mathrm{~mm}$ ( $2.95 \mathrm{inch})$.
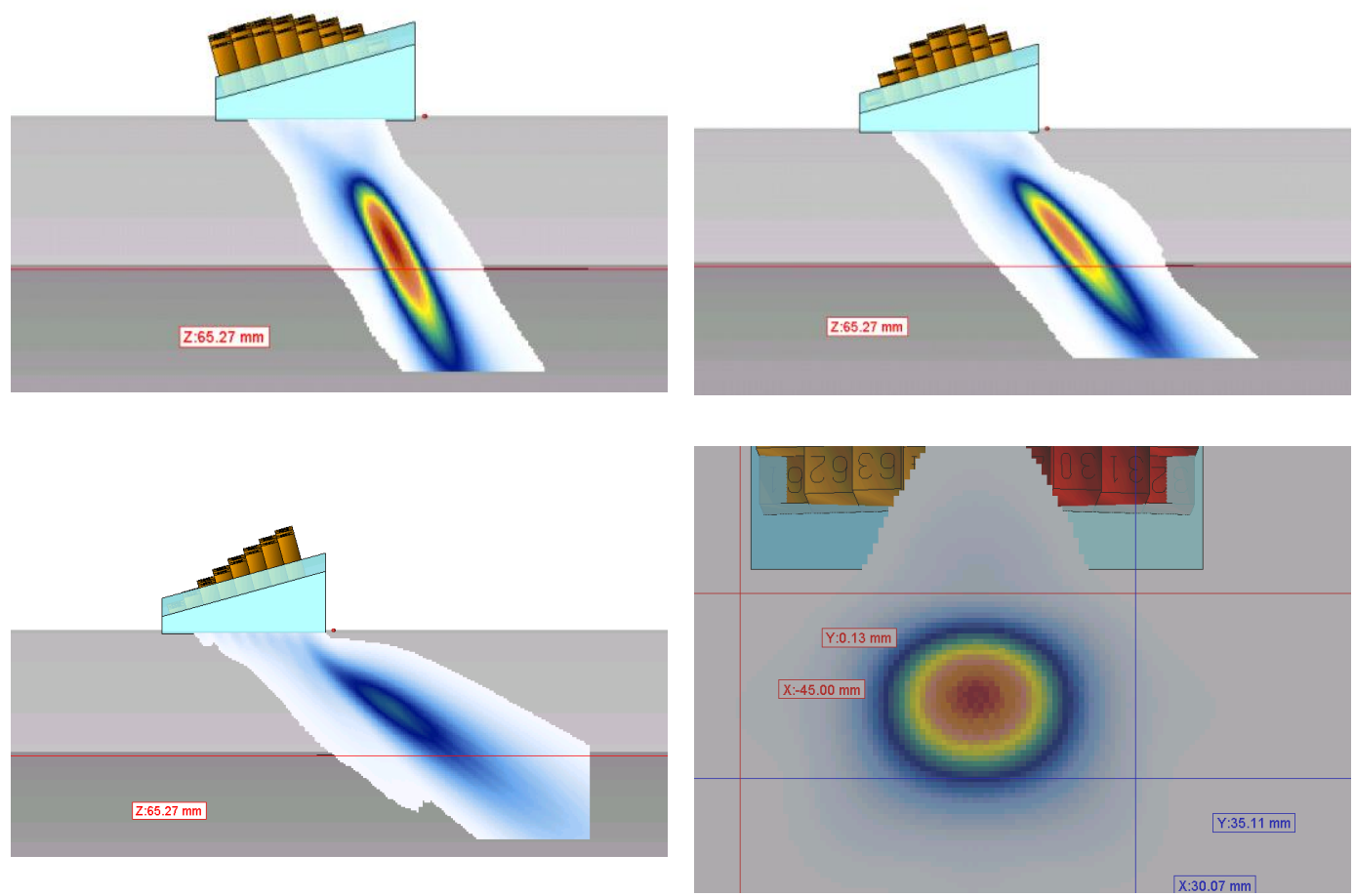

Figure 3.5. PA-2 Sound Field Model Results. The upper left image represents the 30 degree beam, the upper right the 45 degree beam and the lower left the 60 degree beam. The lower right image represents the top view of the 45 degree beam in the focal plane of $65 \mathrm{~mm}$ ( $2.56 \mathrm{inch})$. 


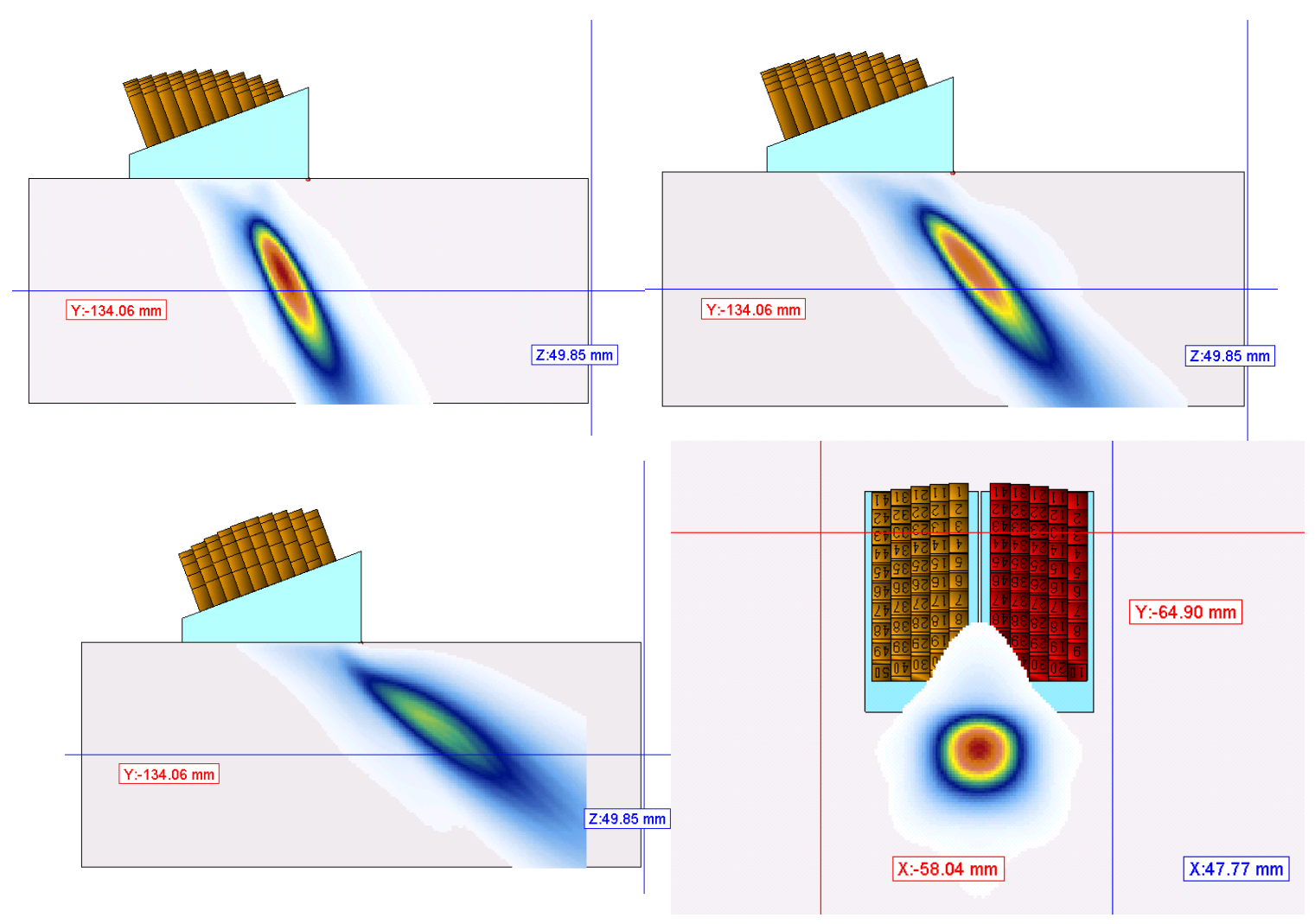

Figure 3.6. PA-3 Sound Field Model Results. The upper left image represents the 30 degree beam, the upper right the 45 degree beam and the lower left the 60 degree beam. The lower right image represents the top view of the 45 degree beam in the focal plane of $50 \mathrm{~mm}$ (1.97 inch). 



\subsection{Ultrasonic Phased-Array Acquisition Configuration}

Data collected via the PA-1 and PA-2 probes were acquired with a Tomoscan III ${ }^{\circledR}, 32$-channel instrument produced by ZETEC, Inc. (formerly R/D Tech, Inc.). This instrument can be programmed to control up to 32 channels for transmission and reception of ultrasonic signals. Its square wave pulser will drive probes ideally in the $1.0-20 \mathrm{MHz}$ range. The longest programmable pulse duration is 500 nanoseconds (ns), which is optimal for a $1.0 \mathrm{MHz}$ probe. A modified system was used for this data acquisition that enabled reception down to $200 \mathrm{kHz}$, but again, the pulser was not designed for signals below 1.0 MHz. Data acquisition for the PA-3 probe was accomplished using a ZETEC DYNARAY ${ }^{\circledR}$ system. This commercially available instrument is equipped to accommodate a maximum of $256 \mathrm{PA}$ channels and requires the use of UltraVision $3^{\circledR}$ software. Its frequency pulsing electronics will drive probes in the $0.2-20 \mathrm{MHz}$ range. The system has a maximum pulse duration of $1000 \mathrm{~ns}$, which is ideal for optimizing the bandwidth of a $500 \mathrm{kHz}$ probe. Phased-array data were acquired over a range of inspection angles from 30 degrees to 60 degrees in 1-degree increments for line scans and 30 degrees to 60 degrees in 3-degree increments for raster scanning.

PA-1 line scan data were acquired with a spatial resolution (step size) of $2.54 \mathrm{~mm}(0.1 \mathrm{in}$.). Scan lengths were typically in the $130 \mathrm{~mm}$ (5.12 in.) range. A true depth focus at $75 \mathrm{~mm}$ (2.95 in.) was used.

PA-2 line scan data were acquired with a spatial resolution (step size) of $2.0 \mathrm{~mm}(0.08 \mathrm{in}$.). Scan length were typically in the $130 \mathrm{~mm}$ (5.12 in.) range. Insonification angles of $30-60 \mathrm{deg}$ with $1 \mathrm{deg}$ increments were used with a true depth focus at $65 \mathrm{~mm}$ (2.56 in.).

PA-3 line scan data were acquired with a spatial resolution of $1.0 \mathrm{~mm}(0.04 \mathrm{in}$.). Scan lengths were slightly longer at approximately $140 \mathrm{~mm}$ (5.51 in.) or more, as the specimen allowed. The scan lengths were larger than those obtained with the other two probes since the probe footprint was smaller.

Refracted angles were swept from 30 to $60 \mathrm{deg}$ with 1-degree increments, and a half path focus at $50 \mathrm{~mm}$ (1.97 in.) was used. A 200 volt pulse with a $1000 \mathrm{~ns}$ pulse width and $40 \mathrm{~dB}$ of hard gain were also employed. These parameters will be further discussed in Section 5. 



\subsection{Data Comparison}

A comparison of the three phased-array probes was conducted using responses from each array on flaws in the PWROG specimens. Performance analyses were based on flaw detection and local signal-tonoise calculations of the detected flaws. The combination of the newest PA-3 probe design with enhanced system pulsing electronics should have produced a more broad-band ultrasonic signal at a lower center frequency signal in the material. However, it was noted that received signals were in fact similar in frequency content for all three probes. A very limited sampling of the data showed that the flaw signals were typically in the $450-500 \mathrm{kHz}$ range. This topic is discussed further but suggests that the material itself naturally filters out the higher and lower frequencies and primarily only supports signals in this frequency range.

The first sets of data using PA-1 were acquired in 2004 and 2005. The second set of data with PA-2 were acquired in 2006, and the most recent data with PA-3 in 2009. In addition to changes in transducers and electronics, the scanning protocol has evolved as well. These factors are considered in the data comparison that follows. The basis for this limited comparison is the response from three flaws, as was previously mentioned. Base material data were acquired with the later two probes but not for PA-1, so comparisons predicated on corner signal responses that provide an indication of signal loss over some circumferential scan range are not possible. The three flaws that form the basis of the comparison include one that was an easily detected flaw, with the other two more difficult to detect. Other considerations are the type of flaw, flaw dimensions, morphology, and material grain size. An earlier PNNL study (Anderson et al. 2007) based on the examination of 15 PWROG CASS specimens showed that the PA-2 probe detected nearly all (93\%) of the MFCs and only half (57\%) of the TFCs. The easily detected flaw considered in this comparison is a shallow MFC in a smaller-grained CASS material. The more difficult to detect flaws are both slightly deeper TFCs in larger-grained materials.

\subsection{APE1 Data Comparison}

The first flaw is an estimated $11.4 \mathrm{~mm}$ (0.45 in.), 15.7\% through-wall deep MFC and was readily detected in specimen APE1 by all three PA probes. The flaw is reported to be $39.4 \mathrm{~mm}$ (1.55 in.) long. The line scan results are displayed in Figures 5.1-5.3. The soft gain was set in each image to maximize the flaw response yet keep it below saturation. In each of the figures, the top left image is the sector view, the top right is the C-scan, the bottom left is the A-scan, and the bottom right is the D-scan end view. When possible, the areas represented in each view are nearly equal so a comparison can be made between the three figures. The scan length, which is the horizontal axis in the D-scan end view, is approximately 130-140 mm (5.1-5.5 in.). The depth in this view (vertical axis) is approximately $105 \mathrm{~mm}$ (4.1 in.). 


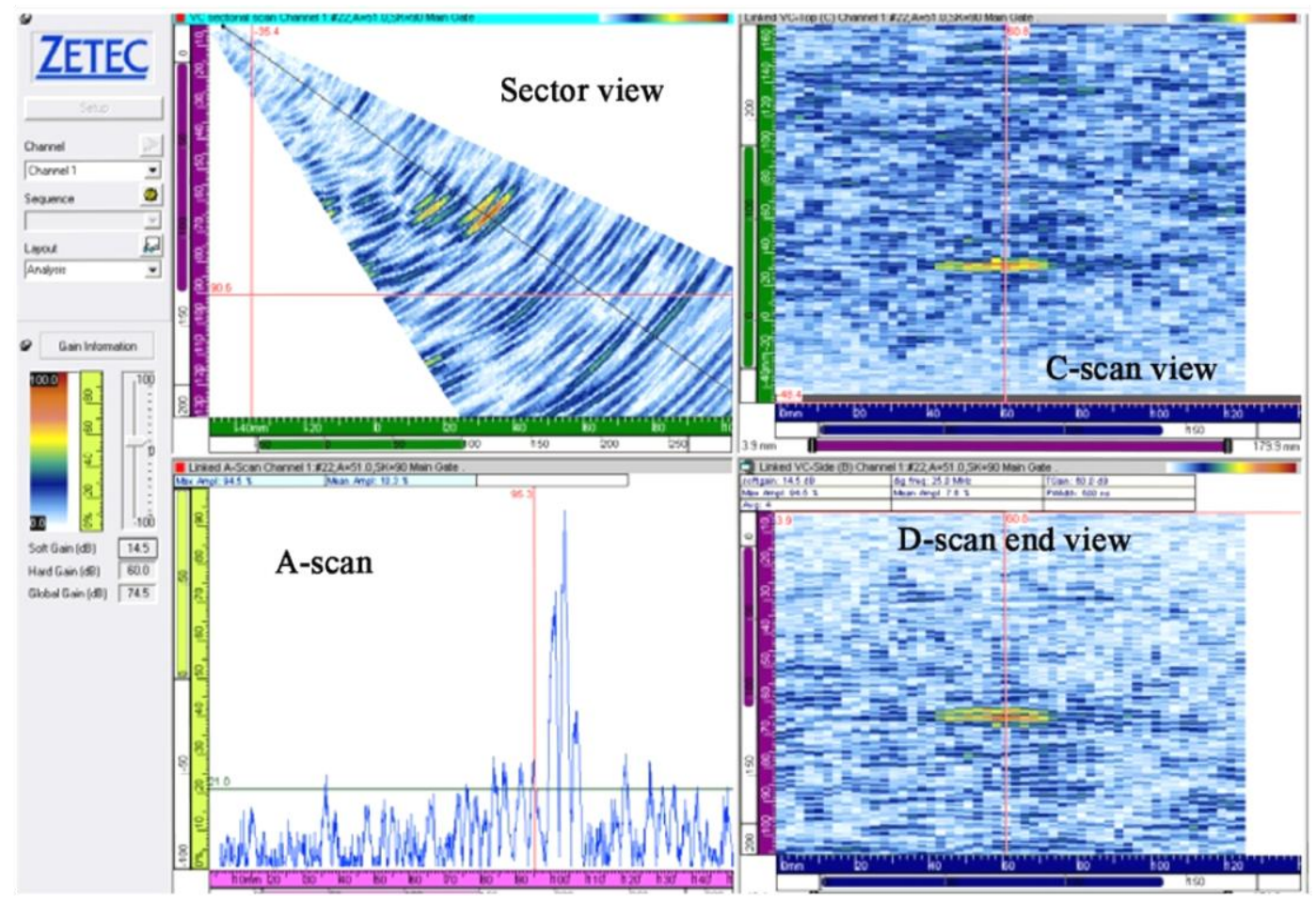

Figure 5.1. PA-1 Data from APE1 at 3.5 Inches $(88.9 \mathrm{~mm})$ from the Weld Centerline. The flaw is observed at 51 degrees.

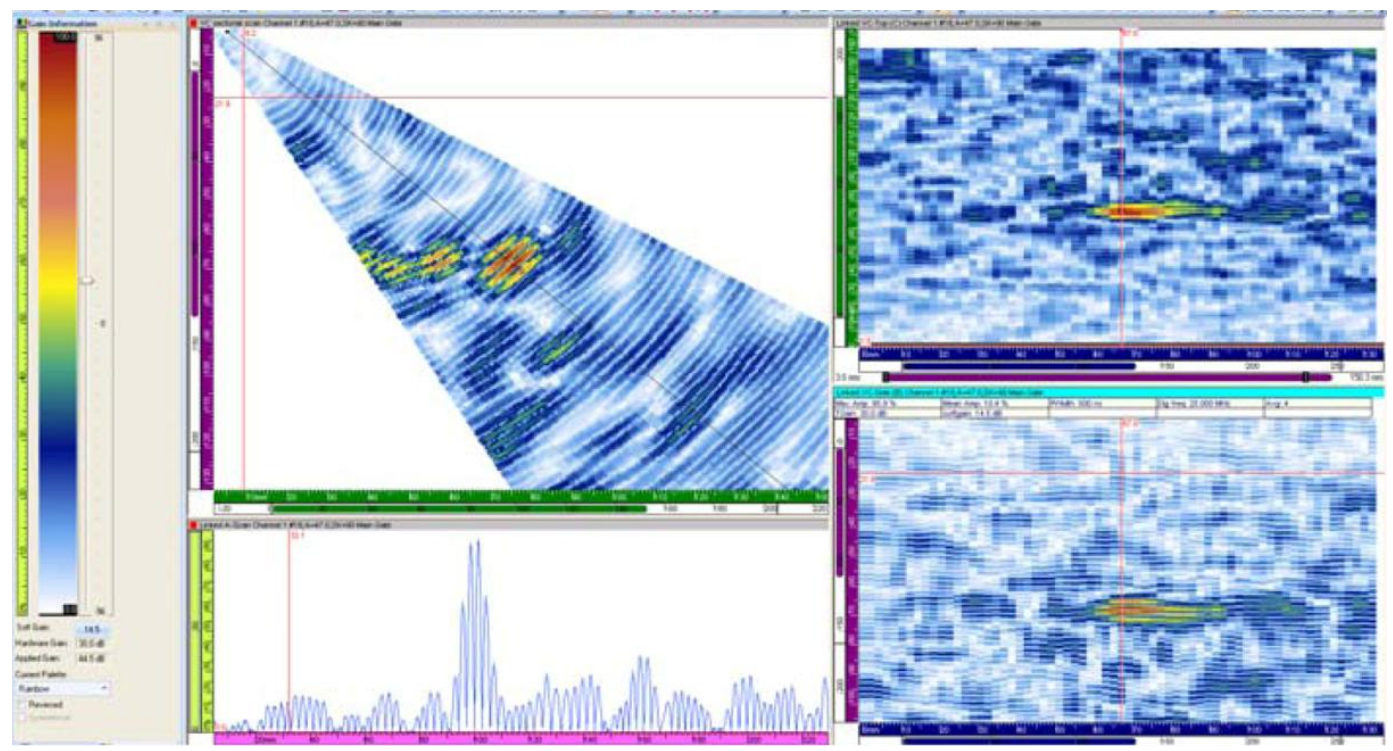

Figure 5.2. PA-2 Data from APE1 at 3.0 Inches $(76.2 \mathrm{~mm})$ from the Weld Centerline. The flaw is observed at 47 degrees. 


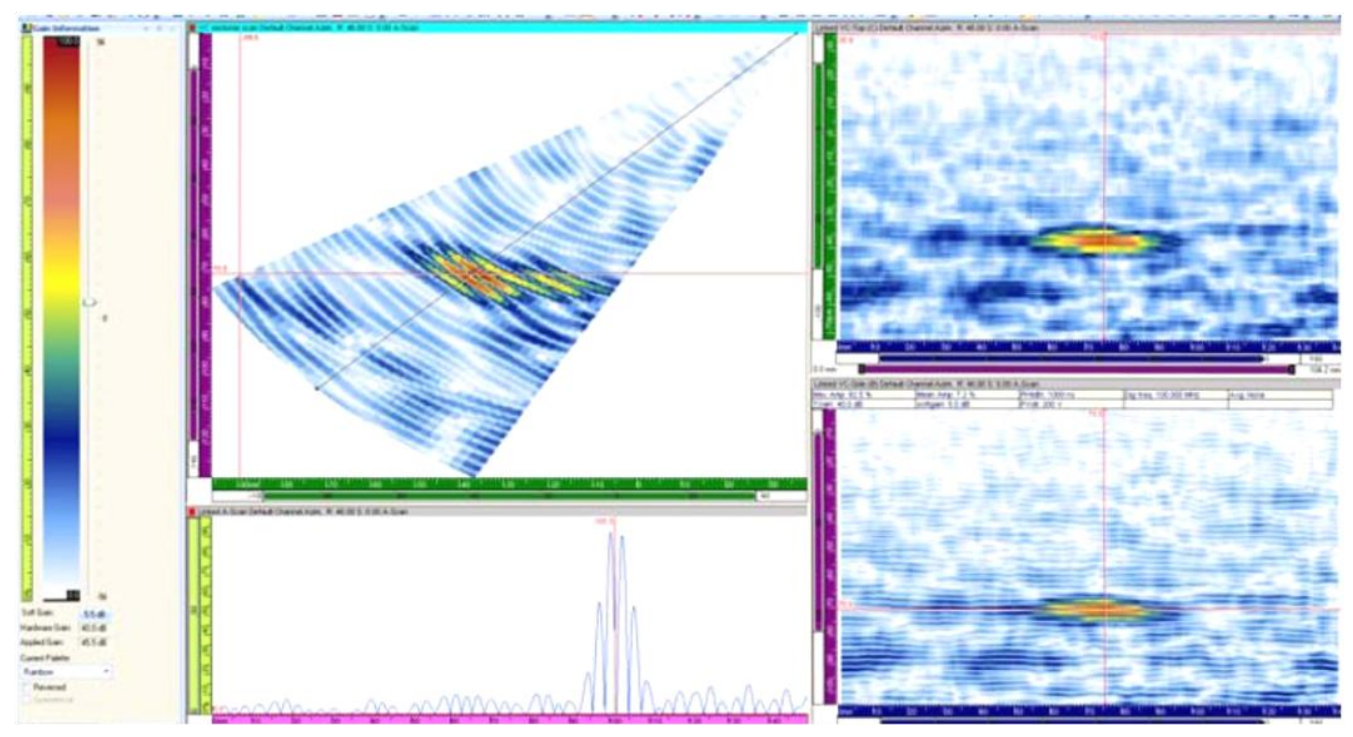

Figure 5.3. PA-3 Data from APE1 at 2.5 Inches $(63.5 \mathrm{~mm})$ from the Weld Centerline. The flaw is observed at 46 degrees.

Other parameters relating to the data acquisition are listed in Table 5.1. Averaging was used to reduce random electronic noise in the signals for the first two probes. The PA-3 data is over sampled and thus leads to larger-than-needed files. Note that the PA-1, piezo-ceramic probe required much more gain, which adds to the system noise that is evident in the data. The piezo-ceramic material was also expected to produce a more narrow-banded signal response, but this is not supported by the data. In fact, the flaw signal contains only three $1 / 2$ cycles with a center frequency of $0.45 \mathrm{MHz}$ whereas the piezo-composite probes both produce a signal with four $1 / 2$ cycles making them more narrow band than the piezo-ceramic signal. The center frequency was determined from the peak to peak separation in the A-scan signal from the flaw. The measured center frequency in the piezo-composite probes is slightly higher at $0.49 \mathrm{MHz}$.

Table 5.1. Data Acquisition Parameters

\begin{tabular}{llll}
\hline \multicolumn{1}{c}{ Probe } & \multicolumn{1}{c}{ PA-1 } & \multicolumn{1}{c}{ PA-2 } & \multicolumn{1}{c}{ PA-3 } \\
\hline Digitizing frequency (MHz) & 25 & 25 & 100 \\
No. of averages & 4 & 4 & 0 \\
Pulse width (nsec) & 500 & 500 & 1000 \\
Pulse voltage (volts) & 180 & 180 & 200 \\
Total gain: hard + soft (dB) & $74.5(60+14.5)$ & $44.5(30+14.5)$ & $45.5(40+5.5)$ \\
No. of $1 / 2$ cycles & 3 & 4 & 4 \\
Frequency (p-p) MHz & 0.45 & 0.49 & 0.49 \\
Scan resolution, step size (mm) (in.) & $2.5(0.1)$ & $2.0(0.08)$ & $1.0(0.04)$ \\
Low pass filter & No & No & $2.0 \mathrm{MHz}$ \\
\hline
\end{tabular}

The radio frequency (rf) A-scans from the flaw in specimen APE1 are displayed in Figures 5.4-5.6 for the three probes. Each A-scan is gated and the frequency response from the calculated Fast Fourier Transform (FFT) is shown. The A-scan from PA-1 shows a high-frequency noise present in the signal that is also confirmed in the FFT results. A low-pass filter might have removed some of this noise but 
was not used. The center frequency and bandwidth values shown in Figure 5.4 are highly dependent on the windowing of the data and should not be considered as an absolute measurement.

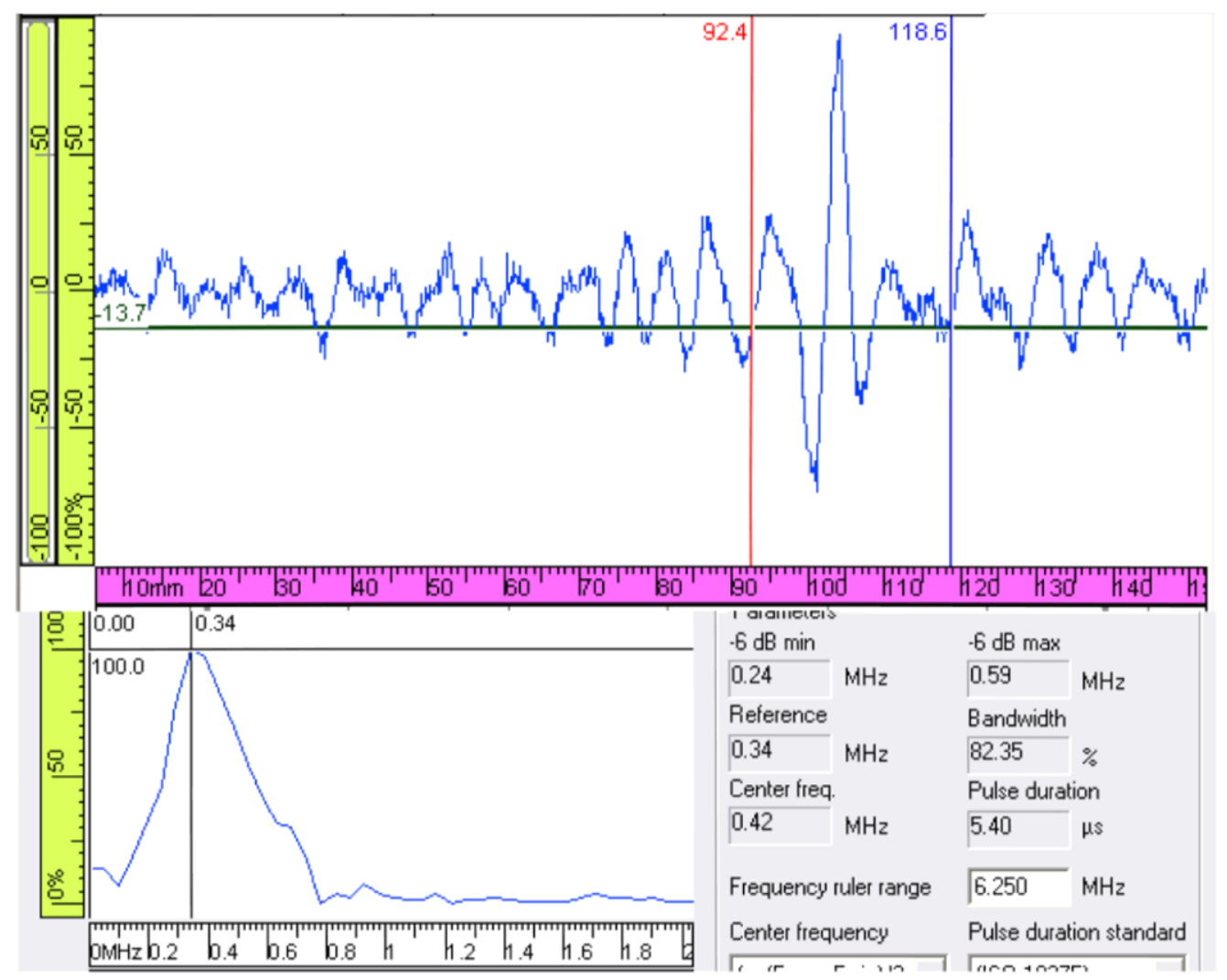

Figure 5.4. PA-1 Data with a Center Frequency of $0.42 \mathrm{MHz}$ and an $82 \%$ Bandwidth (BW)

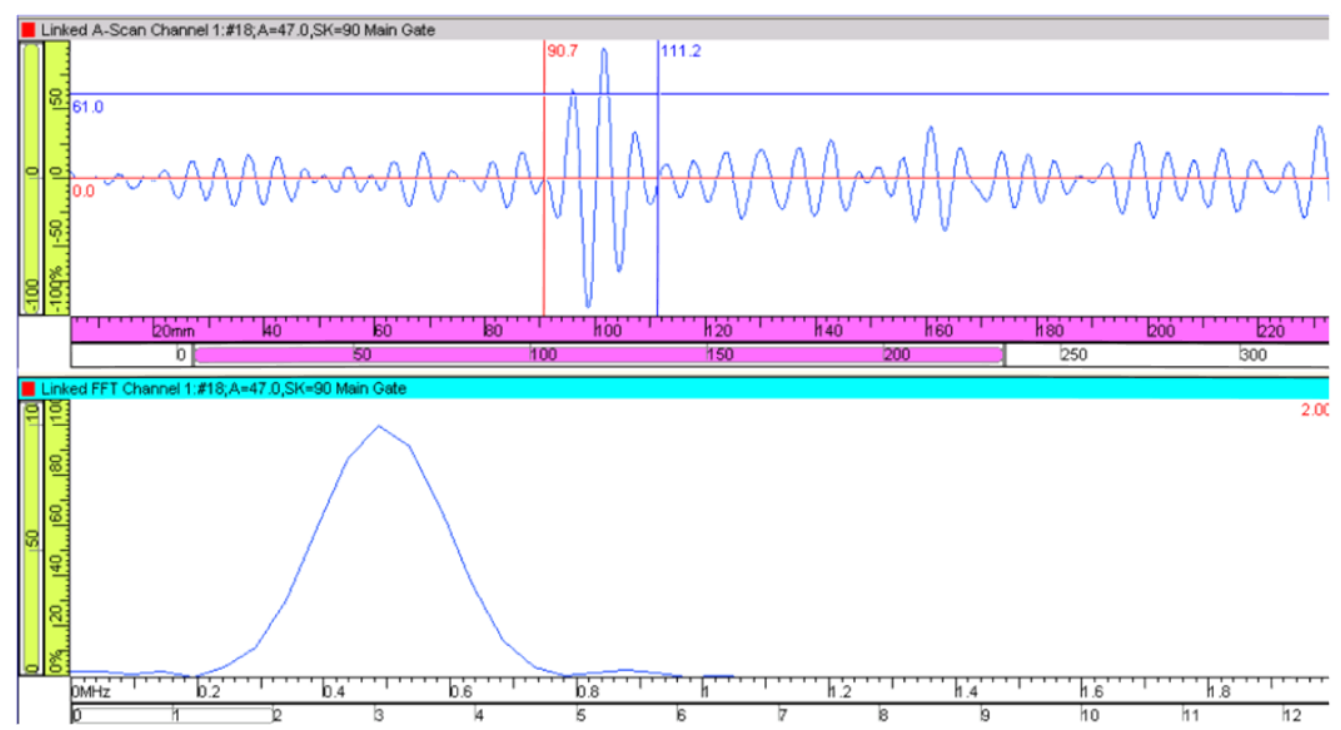

Figure 5.5. PA-2 Data with a Center Frequency of $0.49 \mathrm{MHz}$ and a $60 \% \mathrm{BW}$ 


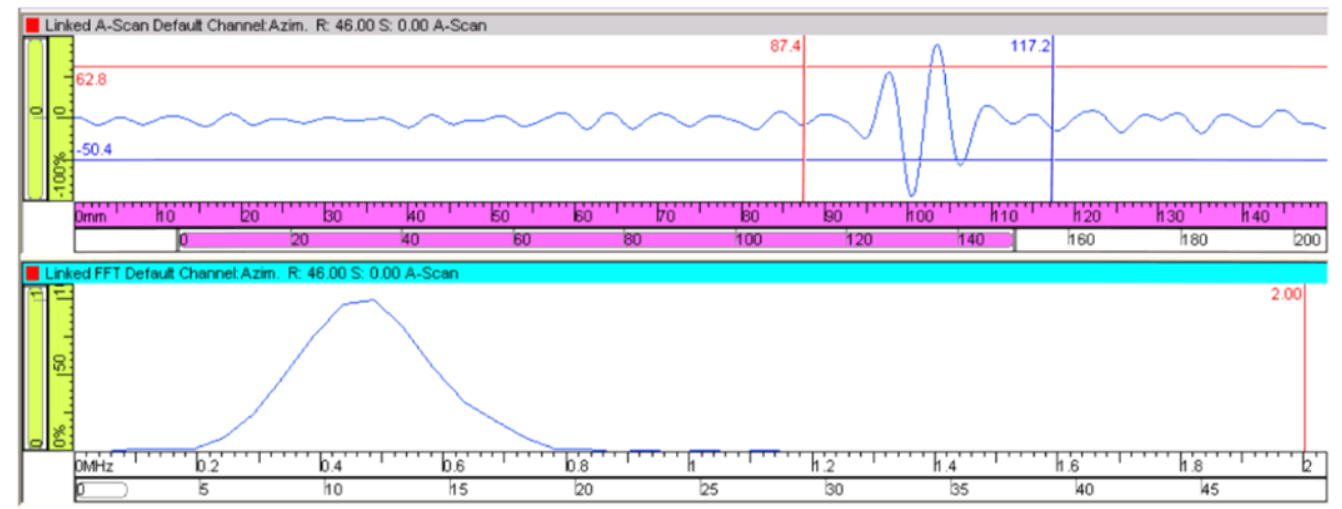

Figure 5.6. PA-3 Data with a Center Frequency of $0.46 \mathrm{MHz}$ and a $73.7 \% \mathrm{BW}$

In addition to the high-frequency noise in the PA-1 signals, this data also suffers from a coarse step size in the scan direction. Even though the probe spot sizes are nominally in the 15 to $20 \mathrm{~mm}(0.59$ to $0.79 \mathrm{in}$.) range and the material grain sizes can be $15 \mathrm{~mm}$ ( $0.59 \mathrm{in}$.) or larger, the smaller step size of $1 \mathrm{~mm}$ (0.04 in.) that was used later with the PA-3 probe improves the image quality and thus the ability to detect a flaw. In summary, flaw discrimination is simplified if a larger cohesive grouping of pixels from a flaw is found in a well-defined (high-resolution) image as opposed to a sparse grouping in a low resolution image.

Signal-to-noise ratio (SNR) was also measured on the flaw data from specimen APE1. SNR values were determined from both an image and an A-scan analysis. In the image analysis, the peak flaw response and the mean noise response at the same part path were recorded from the D-scan end view and formed the SNR value. This results in a lateral comparison of signals in the image at a similar depth. In the A-scan analysis, the peak flaw response and the mean noise response were recorded from one A-scan and formed the SNR value. This analysis gives a comparison of signals through the material (time) at a particular position. The results are listed in Table 5.2. The high-frequency noise added minimally to the SNR values in the PA-1 probe results but did make flaw discrimination more difficult. These data show that PA-3 has the best SNR values, particularly in the A-scan analysis. The data images (Figures 5.1-5.3) further support this conclusion as the PA-3 probe clearly has less material noise, especially at the shallower depths, leading to a higher SNR value from A-scan measurements. The cleaner data at shallower depths will also improve the ability to detect flaw tips or specular reflectors from the upper parts of a flaw.

Table 5.2. Signal-to-Noise Values (dB) From APE1 Flaw, CCSS Side

\begin{tabular}{lccc}
\cline { 2 - 4 } & PA-1 & PA-2 & PA-3 \\
\hline Image analysis & 19.3 & 17.7 & 20.5 \\
A-scan analysis & 20.2 & 19.6 & 24.8 \\
\hline
\end{tabular}




\subsection{MPE6 Data Comparison}

Data from a "difficult to detect" flaw are compared next from specimen MPE6. The estimated $15.0 \mathrm{~mm}$ (0.59 in.), $23.6 \%$ through-wall deep TFC exhibits branching and the main flaw segment is curved and not entirely parallel to the weld centerline. It is reported to have a $59.2 \mathrm{~mm}$ (2.33 in.) length. This flaw is very different from the MFC in specimen APE1, which is planar and parallel to the weld centerline. The flaw is marginally detected at best with each of the three PA probes evaluated in this study. Figures 5.7-5.9 display the results. A portion of the flaw is possibly detected in each of the images as marked by the angled line in the sector views and by the vertical red reference lines in the Cand D-scan views on the right of these figures. This flaw does not separate well from material noise, as in Figures 5.7 and 5.8, or from geometrical signals such as the ID counter-bore shown in Figure 5.9.

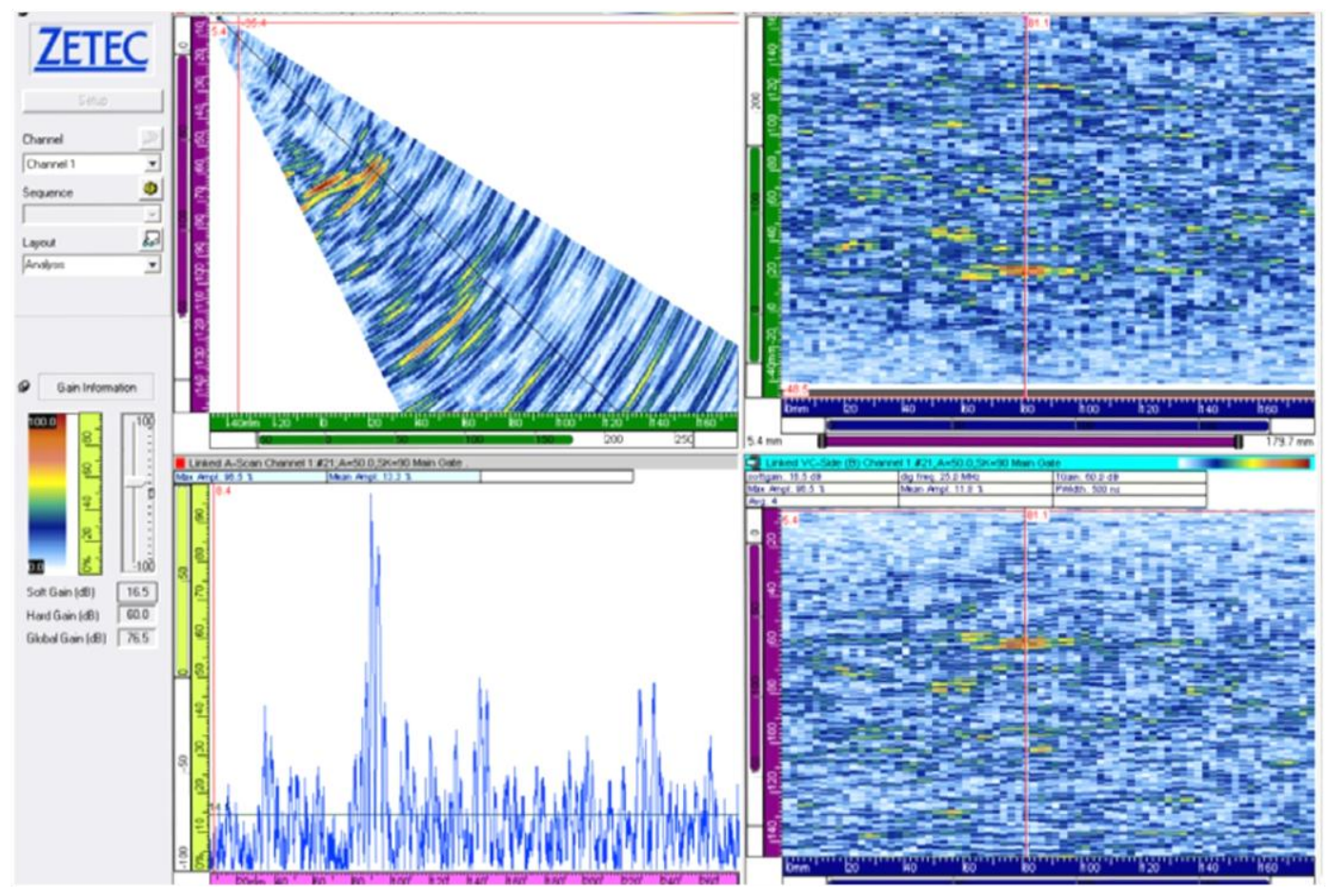

Figure 5.7. PA-1 Data from MPE6 at $3.5 \mathrm{Inch}(88.9 \mathrm{~mm})$ from the Weld Centerline. The indication is observed at 50 degrees. 


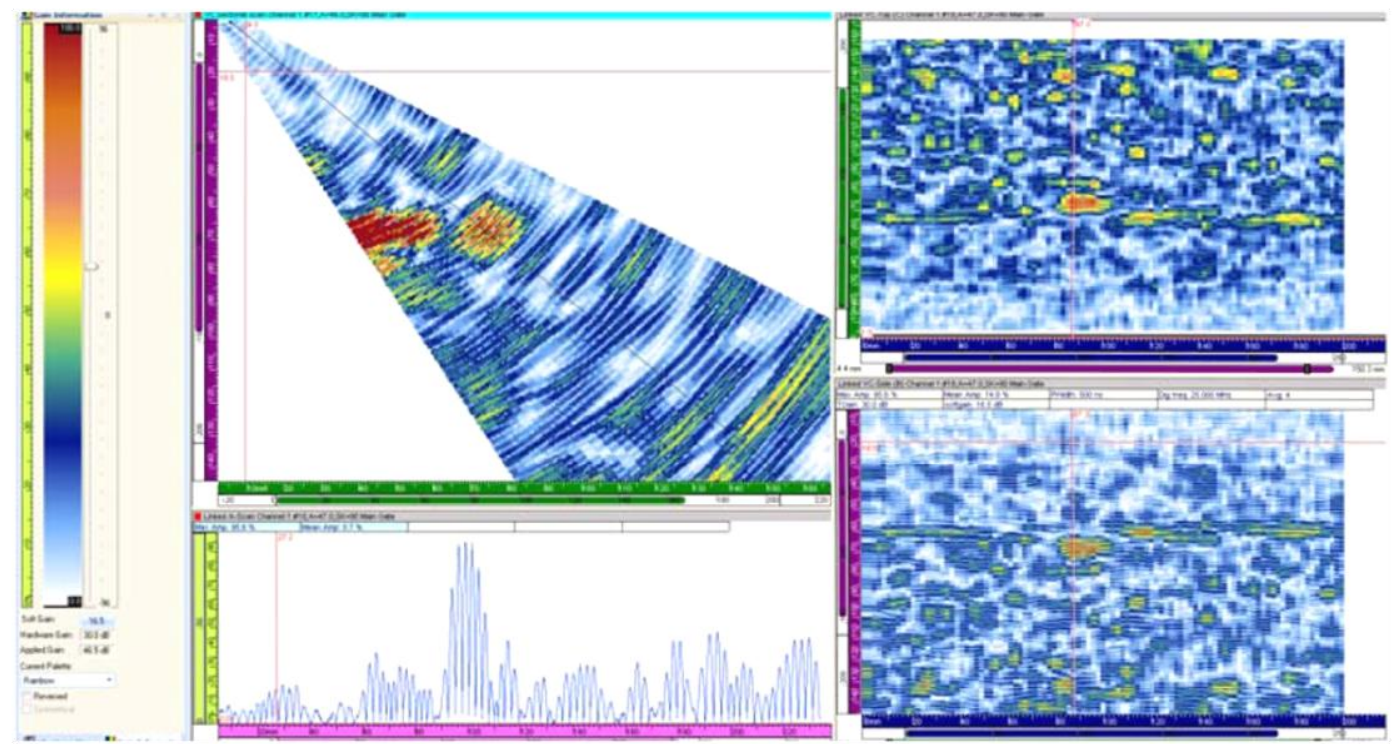

Figure 5.8. PA-2 Data from MPE6 at $3.0 \mathrm{Inch}(76.2 \mathrm{~mm})$ from the Weld Centerline. The indication is observed at 47 degrees.

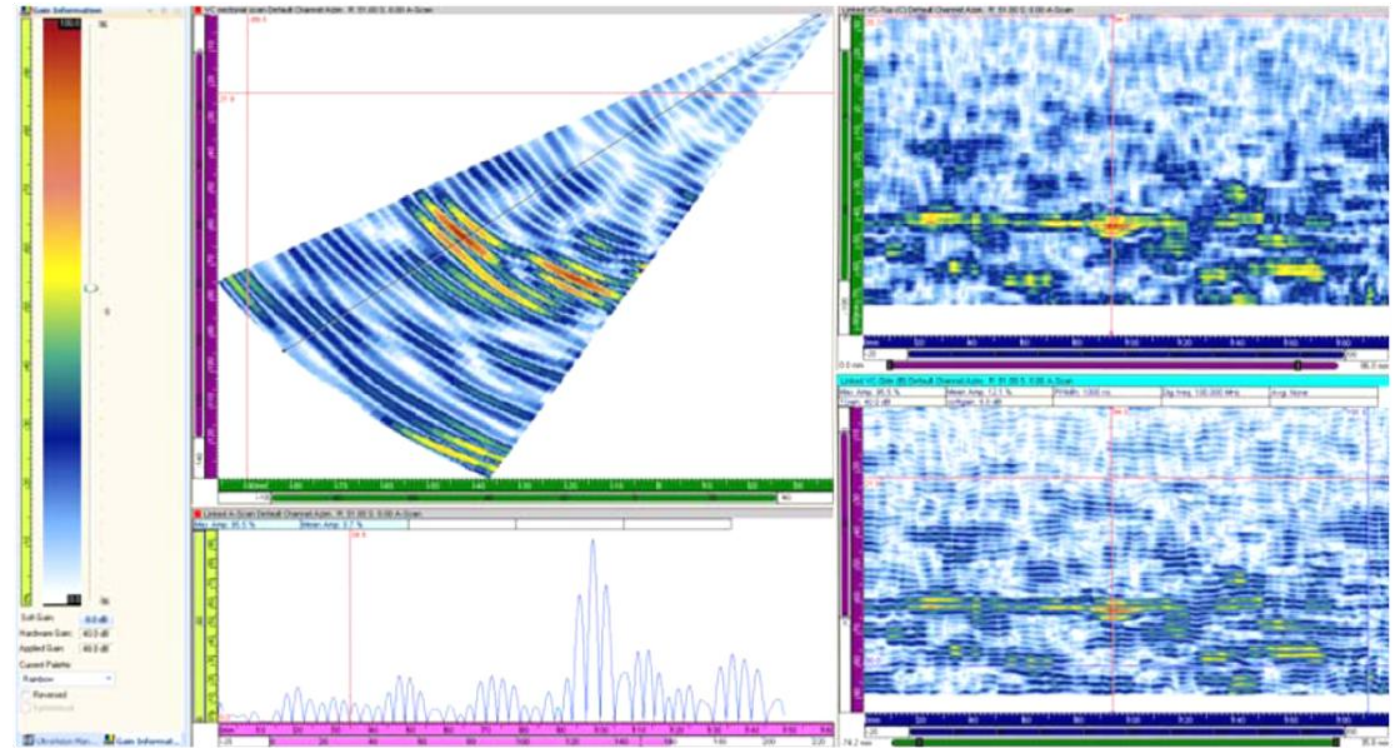

Figure 5.9. PA-3 Data from MPE6 at $3.0 \mathrm{Inch}(76.2 \mathrm{~mm})$ from the Weld Centerline. The indication is observed at 51 degrees.

\subsection{OPE5 Data Comparison}

The third comparison is from the flaw in specimen OPE5. It is reported to be $16.26 \mathrm{~mm}$ (0.64 in.), $29.8 \%$ through-wall deep TFC with a length of $61.47 \mathrm{~mm}$ (2.42 in.). The flaw exhibits branching, but a main portion of the crack is somewhat parallel to the weld centerline. This flaw is detected with the three PA probes with results presented in Figures 5.10-5.13. Figure 5.10 represents the PA-1 data and again 
exhibits high-frequency noise. This data was acquired with the probe center positioned 3.0 inch $(76.2 \mathrm{~mm})$ from the weld center line. The end view and top view images are also pixilated as a result of the coarse scanner step size. However, the flaw response is identified in the sector view and is separated from the saturated geometrical (counter-bore) signal to its left at lower angles.

The data from PA-2 was acquired with the probe positioned closer to the weld. The center of the probe was positioned 2.0 inches $(50.8 \mathrm{~mm})$ from the weld centerline. In this data, Figure 5.11, the counter-bore signal is not part of the scanned aperture. The flaw signal is more complex and shows reflections from multiple depths.

The data in Figure 5.12 is from PA-3 and was acquired with the probe center approximately 2.0 inches $(50.8 \mathrm{~mm})$ from the weld centerline. This compares well to the Figure 5.11 data from the PA-2 probe. Both files were obtained at nearly the same axial position on the specimen. The counterbore signal is on the edge of the data aperture at low angles with the flaw in the mid-range of angles. Finally, Figure 5.13 was acquired at 2.5 inches $(63.5 \mathrm{~mm}), 0.5 \mathrm{inch}(12.7 \mathrm{~mm})$ further from the weld centerline with the PA-3 probe. The signals in the sector view are similar to the signals from PA-1 in Figure 5.10. Both show a large counterbore signal at lower angles and the flaw at the upper angles. However, the data from PA-3 have better SNR values and present a more cohesive response from the flaw than the data from PA-1.

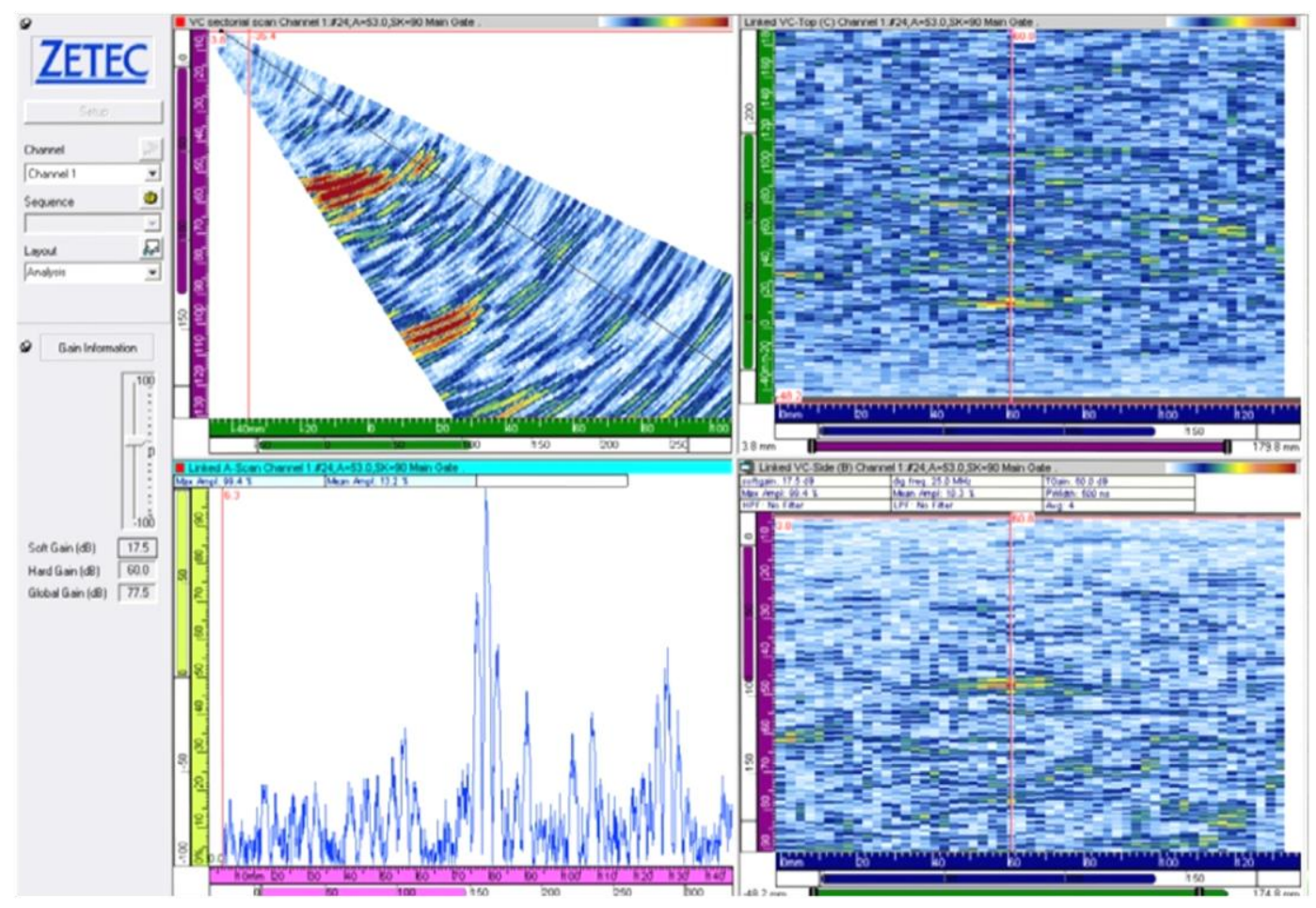

Figure 5.10. PA-1 Data from OPE5 at $3.0 \mathrm{Inch}(76.2 \mathrm{~mm})$ from the Weld Centerline. This indication is observed at 53 degrees with $60+17.5 \mathrm{~dB}$ of gain. 


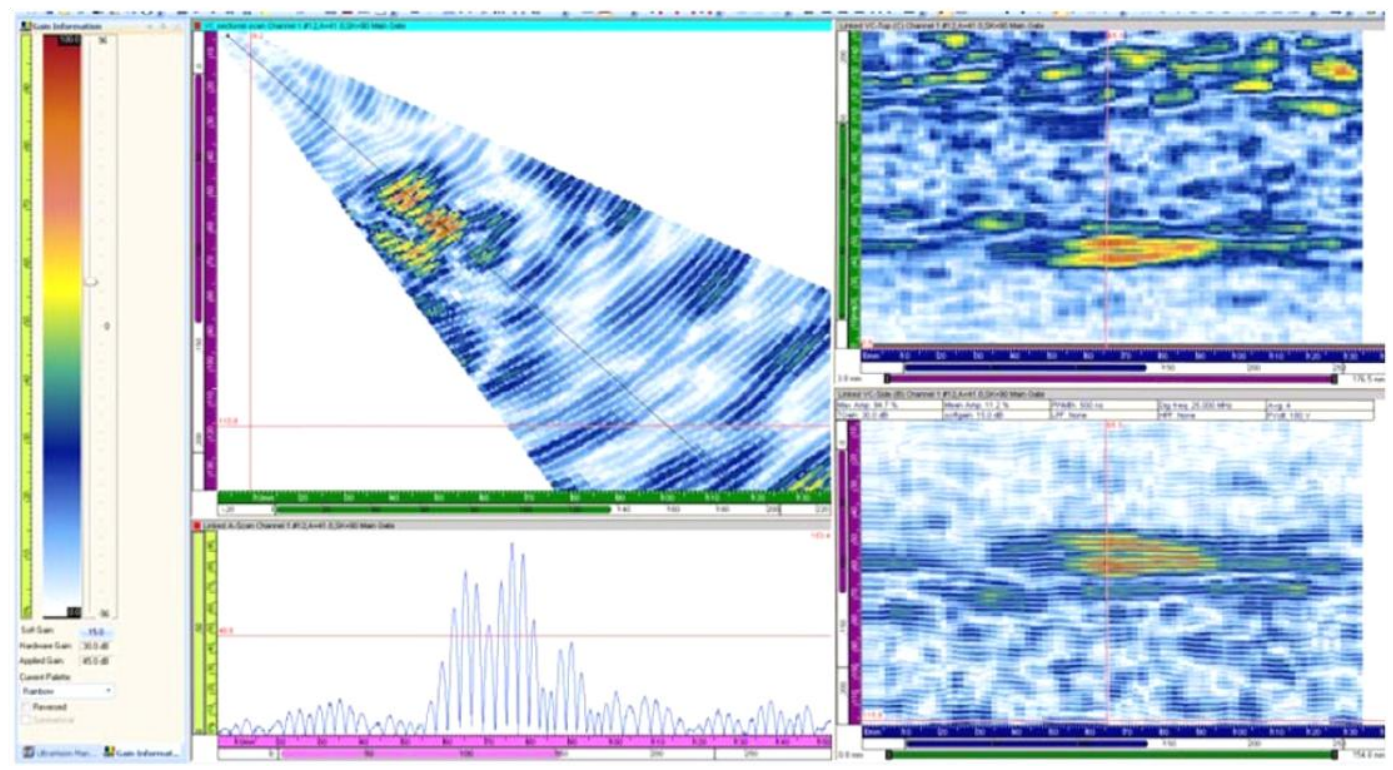

Figure 5.11. PA-2 Data from OPE5 at $2.0 \mathrm{Inch}(50.8 \mathrm{~mm})$ from the Weld Centerline. The indication is observed at 41 degrees with $30+15 \mathrm{~dB}$ of gain.

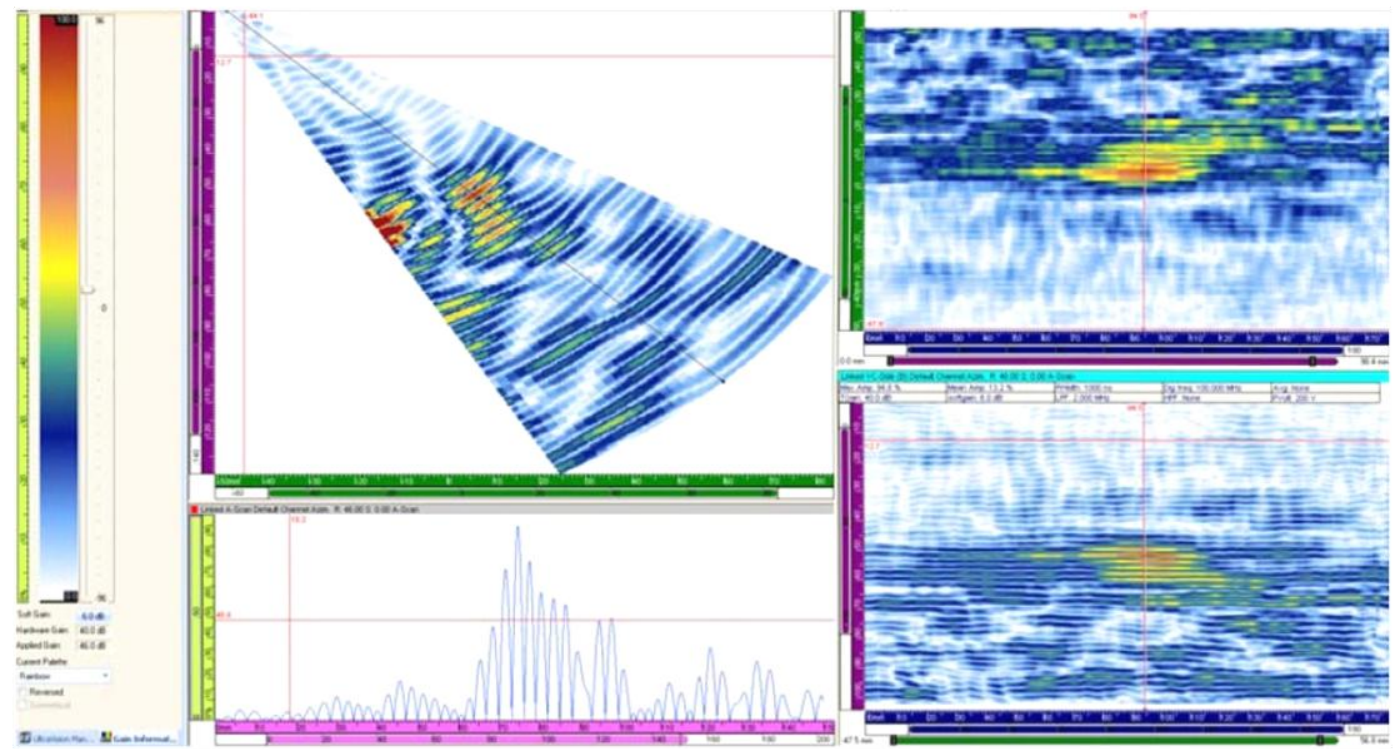

Figure 5.12. PA-3 Data from OPE5 at $2.0 \mathrm{Inch}(50.8 \mathrm{~mm})$ from the Weld Centerline. The indication is observed at 46 degrees and $40+6 \mathrm{~dB}$ of gain. 


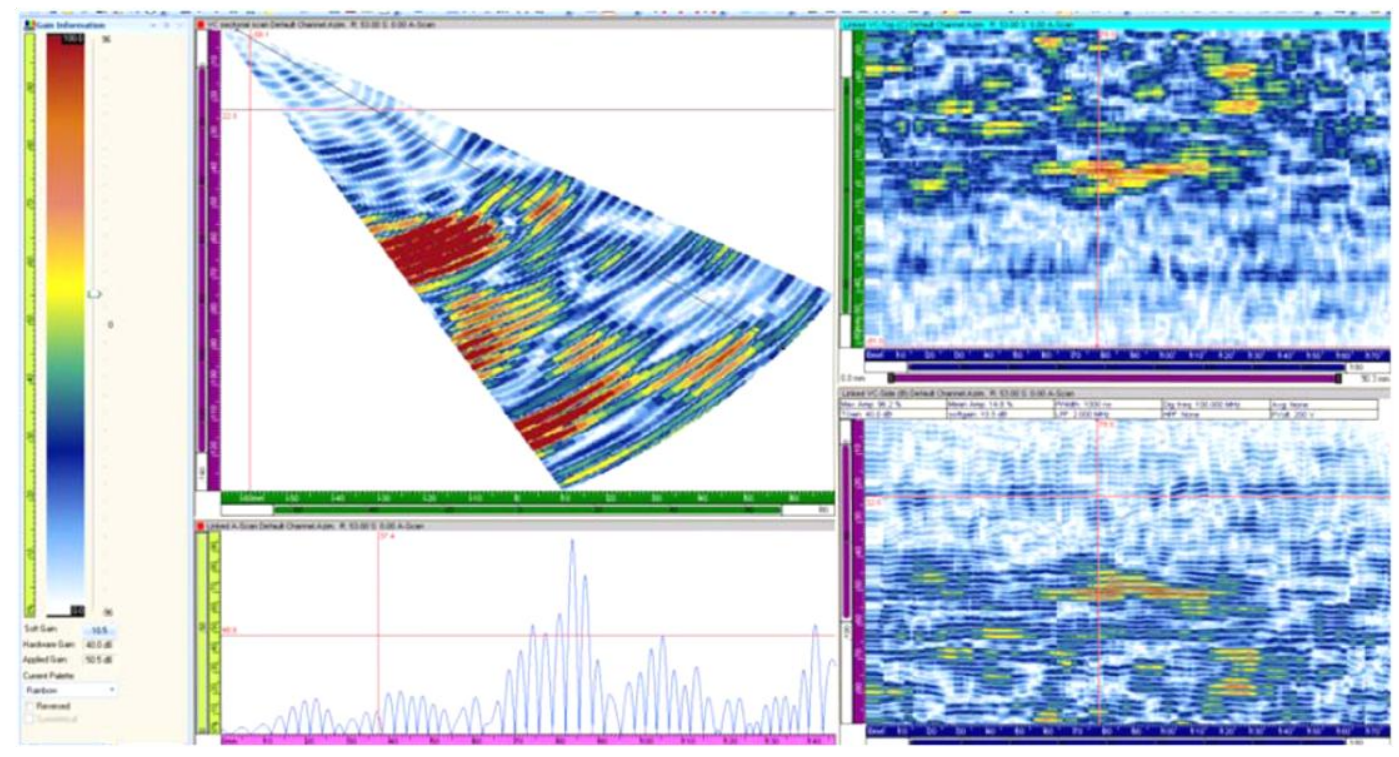

Figure 5.13. PA-3 Data from OPE5 at $2.5 \mathrm{Inch}(63.5 \mathrm{~mm})$ from the Weld Centerline. The indication is observed at 53 degrees and $40+10.5 \mathrm{~dB}$ of gain.

\subsection{Raster Scan Data - PA-3}

Raster data were acquired more recently with the help of an automated scanner. An example of the raster data acquired with the PA-3 probe is shown in Figure 5.14. Data were acquired over the 30 to 60 degree range in three degree steps. This volumetric data set more fully represents the flaw area of interest as compared to line scan data since multiple data lines are acquired in the one file. The D-scan end view on the left and B-scan side view on the right show a possible tip signal or specular reflection from an upper part of the flaw as marked by the arrows. With lower material noise via the PA-3 probe, detection of signals from upper portions of the flaw, or diffracted patterns from flaw tips, becomes a possibility.
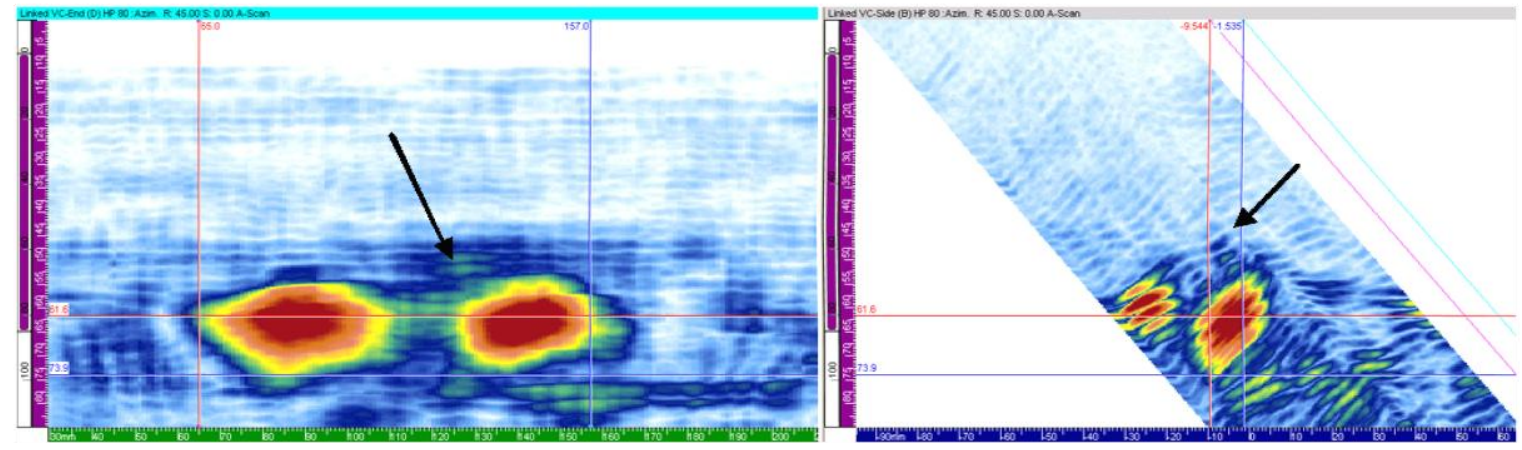

Figure 5.14. Raster Data from INEA4 Showing a Strong ID Signal from the Flaw with a Possible Signal from the Upper Part of the Crack Marked by Arrows. The data represents a 45 degree insonification angle. 


\subsection{Summary and Conclusions}

PNNL has been involved with the inspection of coarse-grained steel reactor components for over 30 years. The most recent efforts have been directed towards the application of low-frequency phasedarray technology. The evolution in design of three 500-kHz PA probes was documented and they were compared based on the flaw responses from several large-bore CASS specimens. In addition to laboratory measurements, beam modeling results and data acquisition protocol were also discussed. The prototype probe was fabricated with piezo-ceramic material while the later two probes were fabricated with piezo-composite materials. The expected increase in probe bandwidth was not seen in the data sets examined, however a large improvement was observed in minimum gain requirements. The piezocomposite probes required approximately $45 \mathrm{~dB}$ of gain while the older probe required $75 \mathrm{~dB}$ of gain, which introduced significant electronic noise in the data. Physically, the footprint of the third-generation probe, PA-3, is reduced in size in the primary direction by $35 \mathrm{~mm}$ (1.4 in.), providing better access to a flawed region. The non-integral wedge design allows for interchangeable wedges to accommodate a variety of specimen geometries and focal laws. More specifically, the wedge angle, roof angle, and beam skewing can be tailored to specimen geometries to provide optimum beam forming and enhanced insonification of the regions of interest. While the newest PA-3 probe was driven at a lower frequency, the measured frequency response from flaws was similar to the older PA-2 probe, with both being greater in center frequency than the PA-1 probe. Finally, an improvement was made with the PA-3 array in reduction of overall noise. This resulted in an increased SNR by as much as $5 \mathrm{~dB}$, and is expected to significantly aid in flaw discrimination and characterization, key factors for coarse-grained material inspections. 



\subsection{References}

Anderson MT, SL Crawford, SE Cumblidge, KM Denslow, AA Diaz and SR Doctor. 2007. Assessment of Crack Detection in Heavy-Walled Cast Stainless Steel Piping Welds Using Advanced Low-Frequency Ultrasonic Methods. NUREG/CR-6933, PNNL-16292, U.S. Nuclear Regulatory Commission, Washington, D.C.

Diaz AA, SR Doctor, BP Hildebrand, FA Simonen, GJ Schuster, ES Andersen, GP McDonald and RD Hasse. 1998. Evaluation of Ultrasonic Inspection Techniques for Coarse-Grained Materials.

NUREG/CR-6594, PNNL-11171, U.S. Nuclear Regulatory Commission, Washington, D.C.

Taylor TT. 1984. An Evaluation of Manual Ultrasonic Inspection of Cast Stainless Steel Piping. NUREG/CR-3753, PNL-5070, U.S. Nuclear Regulatory Commission, Washington, D.C.

Wooh S-C and Y Shi. 1999. "Three-Dimensional Beam Directivity of Phase-Steered Ultrasonic." Journal of the Acoustical Society of America 105(6):3275-3282. 


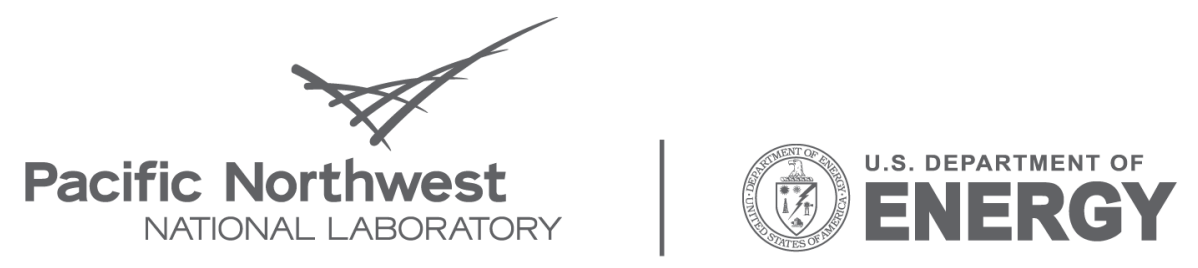

Proudly Operated by Battelle Since 1965

902 Battelle Boulevard

P.O. Box 999

Richland, WA 99352

1-888-375-PNNL (7665)

www.pnl.gov 